\title{
Drivers of digital transformation adoption: A weight and meta-analysis
}

\author{
Diego Rodrigues Cavalcanti $^{\text {a, }}$, Tiago Oliveira $^{a}$, Fernando de Oliveira Santini ${ }^{\text {b }}$ \\ ${ }^{a}$ NOVA Information Management School (NOVA IMS), Universidade Nova de Lisboa, Campus de Campolide, 1070-312 Lisboa, Portugal \\ ${ }^{\mathrm{b}}$ UNISINOS Business School, Universidade do Vale do Rio dos Sinos, Campus de Porto Alegre, 93022-750 Porto Alegre, Brazil
}

\section{H I G H L I G H T S}

- An update of digital transformation (DT) through a weight and meta-analysis.

- Contribution to DT literature by surpassing biases and limitations of size estimates.

- Identification of promising and best predictors for further DT adoption research.

- Behavioral intentions, satisfaction, and habit are best predictors for DT use.

- Usefulness and ease of use are pivotal, being moderated by culture and innovation.

\section{A R T I C L E I N F O}

\section{Keywords:}

Digital transformation

Emerging technologies

Digital disruption

Digital innovation

Adoption theories

Individual adoption

\begin{abstract}
A B S T R A C T
The advent of the global pandemic has accelerated the growing need for product and service transformation, highlighting the emerging importance of technology and creating the opportunity to update the digital transformation (DT) domain through empirical-quantitative research. This weight and meta-analysis enabled the synthesis and integration of previous literature on the scope of individual DT adoption, evaluating the state of the art and filling a void on the subject. Athwart 88 studies and 99 datasets by international sources, our results demonstrate that attitude and satisfaction are relevant predictors of behavioral intentions and promising outcomes, including compatibility and personal innovativeness. Behavioral intentions, satisfaction, and habit are the best predictors for DT use. Usefulness and ease of use are critical for DT adoption intention and use, being moderated by individualism, as a cultural factor, human capital, and knowledge-technology, as innovation indicators. We present a conceptual model of promising and best predictors for future research on DT individual adoption.
\end{abstract}

1. Introduction

The current scenario of high competition and the need for constant innovation makes digital transformation (DT) essential for creating differentiation mechanisms and disruptive business (Jahanmir et al., 2020). Contextualizing the actual society transformed by digital innovation, a report by the world economic forum confirmed the potential of digitalization to generate almost $\$ 100$ trillion in value for companies and communities in the next decade, accelerating social progress (World Economic Forum, 2020).

Defined as the enhancement of existing products through digitization and digital innovation resources (Vial, 2019), DT is a multidisciplinary theme that encompasses changes in several spheres (Verhoef et al., 2021), such as strategy (Matt et al., 2015), people (Navaridas-Nalda et al., 2020), technology (Pillai et al., 2020), culture (Udo et al., 2016), social and organizational structures (Selander and Jarvenpaa, 2016), affecting the way that companies interact with clients (Jain et al., 2021). However, contrary to what many people think, the most relevant sphere for DT is people, since even if technologies evolve quickly, what really matters is whether people are adopting them (Vial, 2019). For Kane (2019), individuals adopt disruptive technologies more quickly than organizations, which often need more time and flexibility to adapt themselves, making room for further investigation into DT individual adoption.

Only in the last ten years was it possible to identify research in information systems disciplines addressing topics such as digitization, digitalization, and DT (Verhoef et al., 2021), which attests to the lack of interest to investigate advances brought by the introduction of

\footnotetext{
* Corresponding author.

E-mail address: rodriguescavalcanti@gmail.com (D.R. Cavalcanti).
} 
disruptive technologies. Recent literature reviews on DT denoted the use of synonyms such as "digital technology" (Matt et al., 2015), as well as myriad definitions of the term, according to technology type, mainly being focused on organizational impact (Vial, 2019). Few studies can be seen at the micro-level, considering disruptive technology adoption through an individual's vision (Meske and Junglas, 2020; Nadkarni and Prügl, 2021), as Verhoef et al. (2021) highlighted greater attention to studies on the adoption of digital technologies and their impact on business only.

As DT brings digital culture premised on giving more power to individuals, increasing its importance in the transformative equation (Guy, 2019), a gap was identified in the literature on individual adoption. Previous research presented conflicts and inconsistencies in results (Blut et al., 2021), considering the wide variation between the effects of main predictors and the outcomes for individual adoption of disruptive technologies, which contradict the conclusions of main adoption models. Some studies found a negative impact for ease of use in behavioral intentions (Çera et al., 2020; Vimalkumar et al., 2021), while others present a strong positive relationship among the same constructs (Khaksar et al., 2021; Pillai et al., 2020). Similarly, for disruptive technology adoption such as DT, a negative relation was found between usefulness and behavioral intentions (Nastjuk et al., 2020; Sobti, 2019), as opposed to the original model's prediction (Venkatesh et al., 2003, 2012), in addition to other studies obtained (Cabrera-Sá nchez et al., 2021; Kabir, 2020). Even for other outcomes such as use behavior, a given study shows a negative relationship with facilitating conditions $(r=-.04$; Chopdar et al., 2018), while other studies adduce a weak impact $(r=.16$; Alam et al., 2021; Vimalkumar et al., 2021), and yet another one accounts for the strong impact of the ratio ( $r=.52$; Netshirando et al., 2020). For Blut et al. (2021), these inconsistencies can be attributed to the non-complete application of the theoretical models, the use of a small sample, or the disregard of variations arising from the different contexts or specificities of the investigated technology.

The presented scenario creates opportunities for investigating the DT phenomenon through the lens of adoption theory (Venkatesh et al., 2003), focusing on individuals to help resolve inconsistencies in previous research, clarify the main DT predictors, and answer why people accept disruptive technologies. This research fills this lacuna by conducting a weight and meta-analysis to review existing studies and systematize the empirical results (Cram et al., 2019), bringing accurate and reliable conclusions to disruptive technologies adoption such as DT. Thus, the objectives are two-fold: 1 ) providing an overview of the pivotal factors for DT adoption under individual focus, proposing a specific and reliable acceptance model; 2) contributing to DT literature by surpassing biases and limitations of size estimates in previous research (Cram et al., 2019), and identifying potential and best predictors for further investigation (Baptista and Oliveira, 2019).

This study is organized as follows. Initially, we broach the research methodology with the problem definition, expound on the studies' selection or rejection criteria, data extraction, and merge the variable process. Then we delve into a descriptive analysis followed by the weight and meta-analysis results and moderation analysis. After, we discuss the findings and implications for theory and practice, and finally, elucidate on the limitations, future avenues for research, and outline the conclusions.

\section{Digital transformation and technology adoption models}

Disruptive technologies have transformed the way companies and individuals interact, making the provision of services and consumption more flexible, evoking the need for continuous innovation. Organizations need to understand the transformative technology adoption process better, as well as the intention, acceptance, and use of those technologies by users to survive in this increasingly dynamic and competitive environment (Jahanmir et al., 2020). For Carroll (2020), technological changes are analogous to transformation, which in turn deal with fundamental changes for carrying out a differentiated job, given market pressures or new opportunities.

In the mid-1990s, the emergence of the commercial internet gave rise to new market and business models, introducing the first ideas about DT and highlighting the central role of IS in value creation processes (Meske and Junglas, 2020). Since then, there has been little evolution in the concept of DT (Vial, 2019), and currently, there is still no fully accepted definition (Mergel et al., 2019). As a multidisciplinary approach, DT is activated by a corporate trigger, as a response by organizations to adopting digital technologies, changing the individual behavior of customers and consumers, and increasing digital competition (Verhoef et al., 2021). DT translates into better interactions between suppliers, customers, and competitors (Singh and Hess, 2017).

Highlighting the lack of studies on the individual human aspects of the topic, Kane (2019) presented his differentiated view of digital transformation with the "technological fallacy," defending the human and organizational aspects as more essential elements than the technological ones. For him, transformative technologies involve changes in how work is performed, making human factors a determinant of organizational digital maturity. In the same direction, Carroll (2020) sought to normalize DT in practice, strengthening the argument that the success of DT does not depend on digital technologies but on the individuals who adopt and use the technology, cultural changes, and organizational processes.

The IS research field, in the last decades, has made great efforts to understand why individuals accept and adopt transformative technologies and how quickly they are used (Davis, 1989; Venkatesh et al., 2003), given that disruptive technologies can raise the level of competition, replacing the old existing pattern (Schmidthuber et al., 2020). Nevertheless, studies on technological adoption can be carried out under different focuses such as individual and organizational (Vimalkumar et al., 2021), in addition to varied theories and models (Rahi et al., 2019), such as the Diffusion Theory of Innovation (DOI) (Rogers et al., 2019), Theory of Planned Behavior (TPB) (Ajzen, 2011), Theory of Rational Action (TRA) (Fishbein and Ajzen, 1975), Social Cognitive Theory (SCT) (Bandura, 1986) and Motivational Model (MM) (Vallerand, 1997), being the most dominant (Mariani et al., 2021) the Technology Acceptance Model (TAM) (Davis, 1989), and the Unified Theory of Acceptance and Use of Technology (UTAUT) (Venkatesh et al., 2003).

A precursor model created to predict attitudes and understand individual behavior in the acceptance of new technologies, the TAM is focused on two constructs considered fundamental to other models, namely, perceived ease of use and perceived usefulness. Since its original proposal, TAM has been evolved to new versions. In 2003, Venkatesh et al. (2003) consolidated different constructs, proposing the UTAUT. After comparing eight adoption models, UTAUT finds that effort expectation, performance expectation, social influence, and facilitating conditions significantly impact the user's intention to adopt technology. Around 2012, UTAUT2 was proposed as the most recent version of the theory applied to the individual consumer and capable of explaining approximately 74 percent of the variations in technology adoption and use from the individual's view (Venkatesh et al., 2012).

Given the relevance of different technologies over existing models, past research has assessed the adoption of different types of disruptive technologies with a transformative focus, such as the autonomous vehicles (Manfreda et al., 2021), internet of things (Ben Arfi et al., 2021b), artificial intelligence (Pillai et al., 2020), blockchain (Queiroz and Fosso Wamba, 2019), Voice-based digital assistants (Vimalkumar et al., 2021), Digital payment (Balakrishnan and Shuib, 2021), mobile payment (Patil et al., 2020), mobile health applications (Alam et al., 2020), Digital Personal Data Stores (Mariani et al., 2021), On-Demand Service Platforms (Delgosha and Hajiheydari, 2020), Business Intelligence and Analytics (Jaklič et al., 2018), social assistive technology (Khaksar et al., 2021), virtual reality (Kunz and Santomier, 2019), besides others considering also varied organizational configurations, as government (Hujran et al., 2020), hospitals (Rahman et al., 2016), schools (Guggemos 
and Seufert, 2021), retail stores (Pillai et al., 2020) and banks (Hu et al., 2019).

With the context presented and understanding that digital transformation is a broad concept capable of being split into three evolutionary stages (e.g., digitization, digitalization, and digital transformation) (Verhoef et al., 2021), we define individual adoption of DT as the degree to which disruptive and transformative technologies are adopted and/or accepted by individuals, whether employees, consumers, customers or citizens, after an improvement event or development of a new product, process or innovation. The main idea about analyzing DT adoption at an individual level is to examine the variables that influence the individual's intention and the respective choices in favor of accepting or rejecting transformative digital technology. Using as an example of DT individual adoption, the analysis of a client from some customer service, which started from face-to-face assistance going to the use of chatbots and artificial intelligence in an online channel, we understand that DT affects organizations and society, changing the interaction between people and services (Carroll, 2020).

\section{Research methodology}

\subsection{Criteria}

The initial step was to define the concept and criteria to be adopted in this search and summarize the research published on DT adoption at an individual level. The first academic definitions for DT appeared in Bowersox et al.'s works in 2005 as a business reinvention process for supply chain management (Schallmo et al., 2017). The subject's importance gave rise to a pervasive variability of definitions (Kraus et al., 2021), and the absence of a common definition initiated the use of synonyms such as digitalization, digitization, digital disruption, and others (Mergel et al., 2019). With a broader definition of DT, it becomes possible to identify studies on the individual, moving away from a definition centered on the organization (Vial, 2019) to something that fits social and individual contexts of transformative technology, closer to the concept of digitalization (Mergel et al., 2019). Thus, an embracing definition was adopted as a process to improve an entity, producing significant changes in its assets through the use of technology and computing, combined with communication and connectivity (Vial, 2019).

Based on previous studies (Mergel et al., 2019; Scott et al., 2019; Verhoef et al., 2021; Vial, 2019), the appropriate keywords for the research were selected, namely DT, transformation, digitalization, digitization, emerging technology, digital disruption, and digital innovation. For adoption theory we used, adoption, intention to adopt, individual adoption, adoption intention, use intention, intention to use, and behavioral intention. All possible combinations, with the logical operators 'AND' and 'OR' connecting the presented keywords for the query (Baptista and Oliveira, 2019), were applied in different research databases: Scopus, ACM digital library, EBSCO, Emerald, Taylor \& Francis, Springer, Web of Science, Science Direct, JSTOR, and Google Scholar. For electronic database searches, two themes were specified. The boolean search strategy was utilized using the term "and" (Gerow et al., 2014): DT subject ("digital transformation" or "digitalization" or "digitization" or "emerging technology" or " digital disruption" or "digital innovation"), and adoption theory ("adoption" or "intention to adopt" or "individual adoption" or "adoption intention" or "use intention" or "intention to use" or "behavioral intention").

The initial search considered all publication types (journals, articles, reviews, conferences, and books) and resulted in more than 1,861 publications between 2014 and the beginning of 2021, requiring refinement. We emphasize that no cut-off point was used and that quantitative studies correlating DT and individual technology adoption in the databases were only found from 2014 onwards. Even so, only around 2018, a considerable evolution was noted in the number of empirical studies related to the topic and has apparently had an evolutionary profile since then.
The second stage involved selecting studies according to general criteria: focus on individual-level analysis, empirical nature and quantitative results, technology adoption theory context, and independent datasets. The result was 124 publications, which were then submitted to new criteria necessary for the meta and weight analysis, as follows: report sample size, statistical coefficients, and written in the English language. The resulting 95 articles also underwent a thorough examination to avoid bias problems (Franque et al., 2020), excluding duplicated publications, same respondents' datasets, studies not related to DT adoption, or those that only cited the selected keywords without a transformative context. Research with multiple independent databases was included, for instance, the studies of (Thakurta et al., 2020) (Scott et al., 2019) (Queiroz and Fosso Wamba, 2019) (Chopdar et al., 2018) (El-Masri and Tarhini, 2017) (Kummer et al., 2017), and (Udo et al., 2016) with two datasets, and (Taghizadeh et al., 2021) with five, resulting in 88 articles ( 85 from journals and three conference papers) and 99 useful datasets, as depicted in Figure 1.

The sample is adequate and allows results generalization (Santini et al., 2019) when compared to recent studies published in top journals, such as (Naranjo Zolotov et al., 2018) with 60 studies (Baptista and Oliveira, 2019), with 54 studies (Franque et al., 2020), with 115 studies, and (Jadil et al., 2021) with 127 studies.

The extraction data process from the 88 selected studies initially involved collecting primary data such as study name, author, place and year of publication, methodology and theories used, geographic origin, quantity and type of sample, and technology. Then, quantitative statistical information on the relations between variables was collected. Names and concepts were merged to assess the relationships between variables and increase meta-analysis precision (Jadil et al., 2021), as similarities were found in original nomenclatures between variables (Blut et al., 2021). The aggregating and re-organizing process followed Venkatesh et al. (2003) approach to allow construct unification. However, given the pronounced variability of technology topics used by authors, it was decided to keep similar but non-identical constructs, such as relative advantage and usefulness; facilitating conditions, perceived behavioral control and compatibility; ease of use, and complexity, as described in Table 1, which provides all codifications and redefinitions of the variables used.

\subsection{Weight and meta-analysis}

As a quantitative technique for analyzing a large number of empirical publications (Jadil et al., 2021), meta-analysis is a theoretical extension tool for the evaluation of models' evolution (Blut et al., 2021), allowing effect size comparison between studies (Geyskens et al., 2009). Meta-analysis makes it possible to generalize results after investigating the set of conclusions obtained from studies adopting different methods, samples, and techniques (Borenstein et al., 2009). Meta-analysis was selected since it offers several benefits (Santini et al., 2019) to examine technology adoption models applied to DT. First, it allows testing assumptions not previously evaluated, quantifying moderating influences, adding and excluding constructs, evaluating and revising variables to expand existing models (Blut et al., 2021). Second, it gives an overview of the constructs in a given research topic, exploring the relationships between predictors and achieved results (Cram et al., 2019). Blut et al. (2021) explained that the last benefit exists in several examples of meta-analysis used to review models in the technology adoption context, such as the TAM, IS success model, TRA and TPB, expectation theory ECM), and the UTAUT.

We used random effects to estimate the statistical summary effect and calculate the studies' variability, which is convergent with this research, preventing extensive studies from dominating the analysis and assuming that effect sizes vary between studies (Borenstein et al., 2009). The meta-analysis covers the most frequently used relations, which occurred three or more times in the 88 selected publications. The meta and weight analysis table presents two initial columns containing 


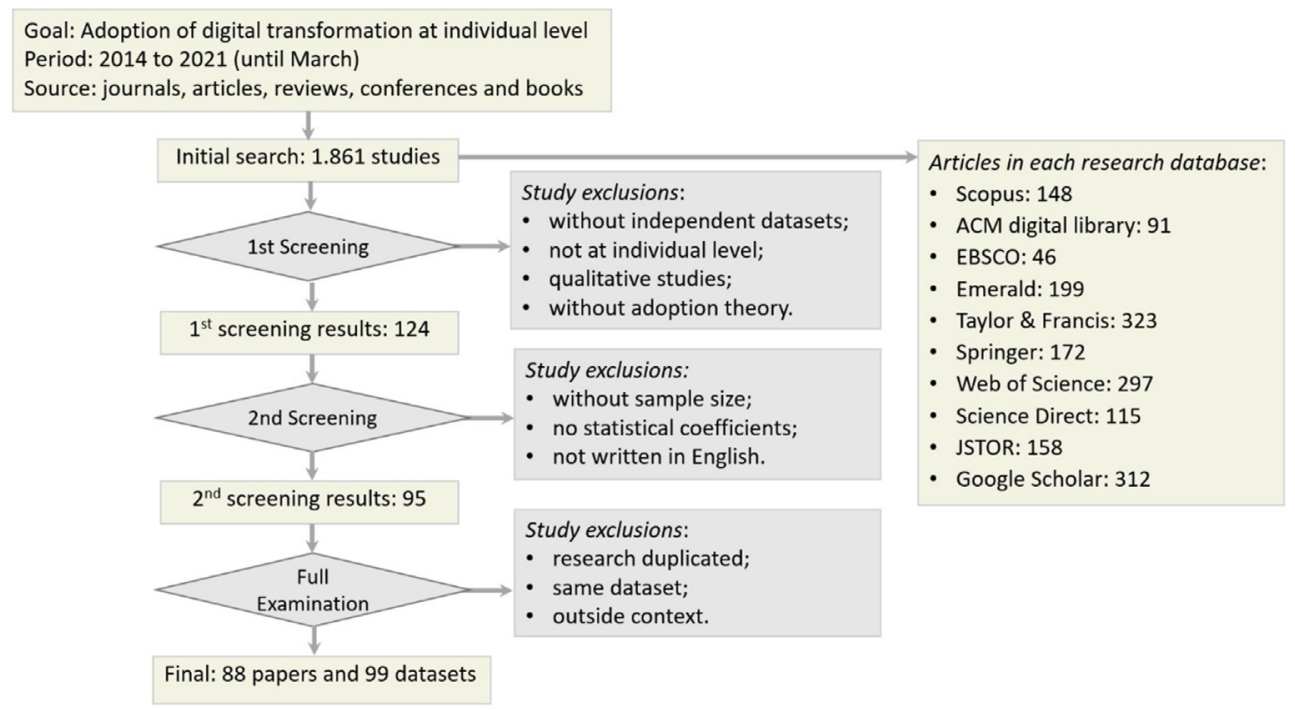

Figure 1. Studies' selection process.

the relationship between dependent and independent constructs. The "Sample" column shows the cumulative samples, "Correlation ( $r$ )" represents the average of correlation coefficients corrected by sample size, "Confidence interval" brings up the lower and upper limit of the 95\% confidence interval (Baptista and Oliveira, 2019). For the FSN, the Rosenthal method was used to verify the number of articles required for the result to be false (Santini et al., 2016), serving to assess relation robustness (Borenstein et al., 2009) and publication bias (Blut et al., 2021).

The $\mathrm{Q}$ and $\mathrm{I}^{2}$ tests were used to assess the significance of heterogeneity among studies ( $\mathrm{p}<0.05)$. The $\mathrm{I}^{2}$ index varies from 0 to $100 \%$, as $25 \%$ represents low and $75 \%$ shows high heterogeneity (Borenstein et al., 2009). After the heterogeneity test, high levels were found in the publications of our dataset since only seven of the 48 relationships are below $90 \%$. The asymmetry test was then performed using Egger regression, which was significant for asymmetry (p-value $>0.10$ for 38 of 48 relationships). However, no evidence was found indicating publication bias in the dataset, but just a high level of heterogeneity, convergent with previous research (Naranjo Zolotov et al., 2018).

The weight analysis was obtained by the ratio of significant variable frequency to the number of tests for the same variable. This technique estimates predictor importance and relationship intensity between constructs (Jeyaraj et al., 2006). The influence of independent variables on dependent ones was analyzed, considering relations examined three or more times (Baptista and Oliveira, 2019; Franque et al., 2020), totalizing 48 relationships. Predictors were classified into (Jeyaraj et al., 2006): (I) "Best Predictors," for relationships among variables explored five or more times in the dataset and weighing more than 0.80 (80\%); and (II) "Promising Predictors," for relations explored four or fewer times in the dataset, and weighing equal to $1(100 \%)$. Weight 1 indicates significance for all relations in the dataset, while weight 0 shows insignificance (Jeyaraj et al., 2006).

\subsection{Moderators}

Regarding the moderators' assessment in adoption models, after revision of the UTAUT model and possible extensions identified in the literature, Venkatesh et al. (2016) cite the need for more studies that show the context of the theoretical application of adoption models. Further studies on technology adoption encompassing different moderators are needed to understand the variability of organizations, cultures, and various technologies as contextual predictors of UTAUT (Blut et al.,
2021). We selected gross domestic product (GDP), cultural factors, and innovation factors as moderators. Economic differences such as the income level between countries is also a relevant factor since the Tallon \& Kraemer framework relates different use and adoption of technology according to a country's economic development (Švarc et al., 2020). As societies with higher income levels have a greater economic capacity and ample access to resources, which positively influences disruptive technology adoption (Kim and Peterson, 2017), a stronger relationship between individual adoption of DT is expected in countries with higher GDP.

Given the importance of the innovation index for DT adoption, individual indicators that build the index were measured. The individual indicators developed by the world intellectual property organization (WIPO, 2020) are institutions (like political, regulatory, and business environment subdimensions), human capital and research (including education, tertiary education, and research \& development - R\&D), infrastructure (with ICTs, general infrastructure, and ecological sustainability), market sophistication (like credit, investment, trade, competition, and market scale), business sophistication (with knowledge workers, innovation linkages, and knowledge absorption), knowledge and technology outputs (with creation, impact, and diffusion of knowledge), and finally creative outputs (like intangible assets, creative good-services, and online creativity). A strong relation among individual adoption of DT is expected in countries with a higher innovation index since individuals from nations with high innovative rates tend to have greater skills, structure, and competencies (Santini et al., 2019) to adopt new technologies.

As cultural variability can influence individual behavior, explaining technology use in different cultures (Peña-García et al., 2020; Srite and Karahanna, 2006), the original Hofstede's model with four factors for cross-country comparisons was used: power distance, individualism, masculinity, and uncertainty avoidance (Hofstede, 2001).

A stronger relationship between individual adoption of DT in countries with high individualism and masculinity is proposed, considering the focus on advancement, goals, competitiveness, and performance values (Hofstede, 2001; Srite and Karahanna, 2006). A weaker relationship is expected between adoption and disruptive technologies in countries with greater power distances and uncertainty avoidance, given that societies with characteristics of centralization in organizational decisionmaking, process formalization, and resistance to change (Hofstede, 2001) present difficulties and adverse factors to disruptive technology adoption (Chopdar et al., 2018). 
Table 1. Coding and constructs definition.

\begin{tabular}{|c|c|c|}
\hline Construct & Definition & Original names collected in the dataset \\
\hline Attitude & $\begin{array}{l}\text { Positive or negative feelings about the performance of an individual } \\
\text { intended behavior (Fishbein and Ajzen, 1975) }\end{array}$ & $\begin{array}{l}\text { attitude, attitudes content, attitudes technology, attitude toward technology use, } \\
\text { Attitude Toward Using, Attitude Toward Use, Attitude Toward transition, Users } \\
\text { Attitude, Overall attitude }\end{array}$ \\
\hline Behavioral Intentions & $\begin{array}{l}\text { The strength of the individual intention to perform a certain behavior } \\
\text { (Fishbein and Ajzen, 1975) }\end{array}$ & $\begin{array}{l}\text { acceptance intentions, adoption, adoption intentions, behavior intentions, behavioral } \\
\text { intentions to use, continuance intentions, intentions, intentions to actively support, } \\
\text { intentions to adopt, intentions to use, use intentions, usage intentions, customers } \\
\text { intentions, switching intent, switching intention, purchase intentions, interest to use, } \\
\text { routine use intentions, intentions to transition }\end{array}$ \\
\hline Compatibility & $\begin{array}{l}\text { The degree of consistency and adequacy of an innovation to the needs, } \\
\text { experiences, and values of the adopters (Rogers et al., 2019) }\end{array}$ & perceived compatibility \\
\hline Confirmation & $\begin{array}{l}\text { Indicates the validation of the individual's basic expectations after } \\
\text { interaction with a certain context or system use (Bhattacherjee, 2001) }\end{array}$ & - \\
\hline Complexity & $\begin{array}{l}\text { Individual perception about the difficulty of understanding and using } \\
\text { an innovation (Rogers et al., 2019) }\end{array}$ & - \\
\hline Ease of Use & $\begin{array}{l}\text { The degree of ease in using a given technology (Venkatesh et al., } \\
\text { 2003) }\end{array}$ & $\begin{array}{l}\text { effort expectancy, effort expectation, perceived ease of use, pre-adoption effort } \\
\text { expectancy }\end{array}$ \\
\hline $\begin{array}{l}\text { Facilitating } \\
\text { Conditions }\end{array}$ & $\begin{array}{l}\text { Perception about support and available resources for conducting a } \\
\text { behavior (Venkatesh et al., 2003) }\end{array}$ & perceived facilitating condition \\
\hline Habit & $\begin{array}{l}\text { Represents the execution of automatic individual behavior after } \\
\text { learning (Venkatesh et al., 2012) }\end{array}$ & incumbent system habit \\
\hline Hedonic Motivation & Fun or pleasure from the use of technology (Venkatesh et al., 2012) & enjoyment, perceived enjoyment \\
\hline Innovativeness of IT & $\begin{array}{l}\text { Individuals tendency to adopt new technology much earlier and more } \\
\text { frequently than others (Rogers et al., 2019) }\end{array}$ & customer innovativeness, innovativeness, user innovation \\
\hline $\begin{array}{l}\text { Perceived } \\
\text { Behavioural Control }\end{array}$ & $\begin{array}{l}\text { Perceived control when performing a certain behavior (Orbell et al., } \\
\text { 1997) }\end{array}$ & perceived behavior control \\
\hline Perceived Costs & $\begin{array}{l}\text { Refers to general transaction costs, involving time and effort perceived } \\
\text { by the individual (Featherman and Pavlou, 2003) }\end{array}$ & - \\
\hline Perceived Value & $\begin{array}{l}\text { Degree of association between value and usefulness perceived by the } \\
\text { individual, in terms of time and effort invested (Dodds et al., 1991) }\end{array}$ & - \\
\hline $\begin{array}{l}\text { Personal } \\
\text { Innovativeness }\end{array}$ & $\begin{array}{l}\text { Individual characteristic that denotes the willingness to try new } \\
\text { technologies (Agarwal and Karahanna, 2000) }\end{array}$ & perceived personal innovativeness \\
\hline Price Value & $\begin{array}{l}\text { Perception regarding the benefit of something, versus the cost to use it } \\
\text { (Dodds et al., 1991) }\end{array}$ & price, price evaluation, price benefit \\
\hline Privacy Risk & $\begin{array}{l}\text { Possible loss of control over personal information, which is used } \\
\text { without the owner's permission or knowledge (Featherman and } \\
\text { Pavlou, 2003) }\end{array}$ & privacy concerns, privacy, perceived privacy risk, risk \\
\hline Relative Advantage & $\begin{array}{l}\text { Individuals' perception that a recent innovation is better than the } \\
\text { previous one (Rogers et al., 2019) }\end{array}$ & perceived relative advantage \\
\hline Risk & $\begin{array}{l}\text { Perception about uncertainties after expectations about adverse } \\
\text { results from system use (Fu et al., 2006) }\end{array}$ & perceived risk \\
\hline Satisfaction & $\begin{array}{l}\text { Affective emotional reaction after an experience with a certain } \\
\text { technology (Bhattacherjee, 2001) }\end{array}$ & user satisfaction, perceived satisfaction \\
\hline Self-Efficacy & $\begin{array}{l}\text { Individuals' belief about the ability to perform specific tasks using a } \\
\text { system (Venkatesh, 2000) }\end{array}$ & computer self-efficacy, post-adoption self-efficacy \\
\hline Self-Quarantine & $\begin{array}{l}\text { Restriction of people who are presumed to have been exposed to a } \\
\text { contagious disease (Alam et al., 2021) }\end{array}$ & - \\
\hline Social Influence & $\begin{array}{l}\text { User perception of how important people believe that he should use } \\
\text { some technology (Venkatesh et al., 2003) }\end{array}$ & subjective norm, subjective social norm, perceived social influence \\
\hline Trust & $\begin{array}{l}\text { Perception of reliability, which involves a set of beliefs related to } \\
\text { integrity, benevolence, and competence (Gefen et al., 2003) }\end{array}$ & $\begin{array}{l}\text { consumer trust, trust belief, users trust, trust of stakeholders, trust in the system, } \\
\text { perceived trust, trust concerns }\end{array}$ \\
\hline Use Behavior & $\begin{array}{l}\text { Current use of the system from the point of view of technology } \\
\text { acceptance (Davis, 1989) }\end{array}$ & $\begin{array}{l}\text { actual usage, actual usage behavior, actual behavior, adoption, technology adoption, use } \\
\text { behavior, usage, intentions to continue usage, continuance usage intentions, usage } \\
\text { behavior, objective use, service use }\end{array}$ \\
\hline Usefulness & $\begin{array}{l}\text { The degree to which some technology provides benefits to users when } \\
\text { performing activities (Venkatesh et al., 2003) }\end{array}$ & $\begin{array}{l}\text { expected performance, perceived usefulness, performance expectancy, post-adoption } \\
\text { perceived usefulness, pre-adoption performance expectancy }\end{array}$ \\
\hline
\end{tabular}

\section{Results}

\subsection{Descriptive analysis}

Of the 88 studies found, 85 are articles and three conference papers, with a total of 442 useful relationships (independent-dependent variable) under the criteria of meta-analysis and for weight analysis input. Anent the researched period, more than $88 \%$ (78 publications) refer to the last four years, with nine investigations from 2018, 12 from 2019, 34 from 2020, and 23 publications from 2021 (considering only the first three months of this year), which shows a growing interest in the theme, as shown in Table 2. Respondents' data by country and year (Table 3) confirms the growth trend of DT research from 2016, reaching 13,733 participants in 2020 and 9,046 in 2021, considering only the first three months.

The source analysis reveals that five journals are responsible for almost $45 \%$ of the relevant publications (Technological Forecasting and Social Change, International Journal of Information Management, Computers in Human Behavior, Technology in Society, and Behavior \& Information Technology), with four or more papers each. Considering the 
Table 2. Research studies by source and year.

\begin{tabular}{|c|c|c|c|c|c|c|c|c|c|c|}
\hline $\mathrm{N}$ & Source & 2014 & 2015 & 2016 & 2017 & 2018 & 2019 & 2020 & $2021^{*}$ & Total \\
\hline 1 & African Journal of Science, Technology, Innovation and Development & & & & & & & 1 & & 1 \\
\hline 2 & Asian Economic and Financial Review & & & & & & & 1 & & 1 \\
\hline 3 & Asian Journal of Technology Innovation & & & & & & & 1 & & 1 \\
\hline 4 & Behaviour \& Information Technology & & & & & & & 2 & 2 & 4 \\
\hline 5 & Computer Standards \& Interfaces & & & & & 1 & & & & 1 \\
\hline 6 & Computers in Human Behavior & 1 & & 1 & & 3 & & 1 & 2 & 8 \\
\hline 7 & Decision Support Systems & 1 & & & & & & & & 1 \\
\hline 8 & Educational Technology \& Society & & & & & & & & 1 & 1 \\
\hline 9 & Educational Technology Research and Development & & & 1 & 2 & & & & & 3 \\
\hline 10 & Electronic Commerce Research and Applications & & & & & & 1 & & & 1 \\
\hline 11 & Government Information Quarterly & & & & & & 1 & & 1 & 2 \\
\hline 12 & Health and Technology & & & & & & & 1 & & 1 \\
\hline 13 & IEEE Access & & & & & & & & 1 & 1 \\
\hline 14 & Information \& Management & & & & 1 & & & & & 1 \\
\hline 15 & Information Systems Management & & & & & & & 1 & & 1 \\
\hline 16 & Information Technology \& People & & & & & & & & 2 & 2 \\
\hline 17 & Information Technology for Development & & & & & & & 1 & & 1 \\
\hline 18 & International Conference on Computational Intelligence in Data Science (ICCIDS) & & & & & 1 & & & & 1 \\
\hline 19 & International Conference on Distance Education and Learning (ICDEL) & & & & & & & 1 & & 1 \\
\hline 20 & International Conference on IT Systems and Innovation (ICITSI) & & & & & & & 1 & & 1 \\
\hline 21 & International Journal of Human-Computer Interaction & & & & & & & 1 & & 1 \\
\hline 22 & International Journal of Information Management & & & 1 & & 1 & 4 & 3 & & 9 \\
\hline 23 & International Journal of Medical Informatics & & & & & 1 & & & & 1 \\
\hline 24 & International Journal of Scientific \&Technology Research & & & & & & & 1 & & 1 \\
\hline 25 & International Journal of Technology Management & & & & & & & 1 & & 1 \\
\hline 26 & Journal of Advances in Management Research & & & & & & 1 & & & 1 \\
\hline 27 & Journal of Biomedical Informatics & & & & & & & & 1 & 1 \\
\hline 28 & Journal of Business Ethics & & & 1 & & & & & & 1 \\
\hline 29 & Journal of Business Research & & & & & & & 2 & 1 & 3 \\
\hline 30 & Journal of Computer Information Systems & & & & & & & 1 & & 1 \\
\hline 31 & Journal of Global Operations and Strategic Sourcing & & & & & & & & 1 & 1 \\
\hline 32 & Journal of Innovation \& Knowledge & & & & & & & 1 & & 1 \\
\hline 33 & Journal of Retailing and Consumer Services & & & & & & & 1 & & 1 \\
\hline 34 & Journal of Systems and Information Technology & & & & & & & 1 & & 1 \\
\hline 35 & Machine Learning with Applications & & & & & & & & 1 & 1 \\
\hline 36 & Sport, Business and Management: an international journal & & & & & & & 1 & & 1 \\
\hline 37 & Sustainability & & & & & & & 2 & & 2 \\
\hline 38 & Technological Forecasting and Social Change & & & & & 1 & 2 & 3 & 6 & 12 \\
\hline 39 & Technology in Society & & 1 & & & & 1 & 2 & 2 & 6 \\
\hline 40 & Telecommunications Policy & & & & & & & 1 & & 1 \\
\hline 41 & Telematics and Informatics & & & & & & 1 & 1 & 1 & 3 \\
\hline 42 & The Journal of Academic Librarianship & & & & & & & & 1 & 1 \\
\hline 43 & Tourism Management & & & & & 1 & & & & 1 \\
\hline 44 & $\begin{array}{l}\text { Transforming Government: } \\
\text { People, Process and Policy }\end{array}$ & & & & & & & 1 & & 1 \\
\hline 45 & Transportation Research Part A & & & & & & 1 & & & 1 \\
\hline \multicolumn{2}{|c|}{ TOTAL } & 2 & 1 & 4 & 3 & 9 & 12 & 34 & 23 & 88 \\
\hline
\end{tabular}

Note: * Only the first three months of the year considered.

85 scientific journals used, the impact assessment index (ranking) shows that $75 \%$ are in the first quartile, while $17 \%$ are in Q2 and $8 \%$ in Q3, as Table 2 denotes. The three most used models were TAM $(69 \%-61$ publications), UTAUT (45\% - 40 studies), and UTAUT2 (17\% - 15 studies), as identified in Table 4.

From the 99 datasets, 34,845 respondents were tabulated in total, briefly categorized into groups, according to Table 5. Mobile technologies showed the most respondents $(20,041$ respondents - $58 \%$ of the total), representing its importance for DT as a reference technology, including banking, health, learning, and smartphone payment applications.
Covering 33 countries, respondents' data by country (Table 3) portrays four countries with more than 2,000 people, responsible for $48 \%$ of the total. India has the largest sample size $(7,761$ individuals, with $22 \%$ of total), followed by the United States $(4,281$ people - $12 \%)$, China (2,540 people - 7\%), and Germany (2,454 - 7\%), as depicted in Figure 2 worldwide distribution.

\subsection{Weight and meta-analytic findings}

Only relationships examined three or more times in literature were considered (Santini et al., 2019), resulting in 48 types of relationships 
Table 3. Sample by country and year (ordered by country name).

\begin{tabular}{|c|c|c|c|c|c|c|c|c|c|}
\hline \multirow[t]{2}{*}{ Country } & \multicolumn{8}{|l|}{ Year } & \multirow[t]{2}{*}{ Total } \\
\hline & 2014 & 2015 & 2016 & 2017 & 2018 & 2019 & 2020 & $2021^{*}$ & \\
\hline Albania & & & & & & & 380 & & 380 \\
\hline Australia & & & & 246 & & & & 302 & 548 \\
\hline Austria & & & & & & & 670 & & 670 \\
\hline Bangladesh & & & & & & & 400 & 936 & 1,336 \\
\hline Belgium & & & & & & & 202 & & 202 \\
\hline China & & & & 292 & 284 & 387 & 827 & 750 & 2,540 \\
\hline France & & & & & & & 316 & 535 & 851 \\
\hline Poland & & & 66 & & & & & & 66 \\
\hline Germany & & & & 243 & & 1,067 & 828 & 316 & 2,454 \\
\hline India & & & 331 & & 478 & 1,767 & 3,615 & 1,570 & 7,761 \\
\hline Iran & & & & & & & 582 & 641 & 1,223 \\
\hline Italy & & & & & 51 & & & & 51 \\
\hline Jordan & & & & & & & 302 & 400 & 702 \\
\hline Malaysia & & & & & & & & 809 & 809 \\
\hline Netherlands & & & & & & & 624 & & 624 \\
\hline Oman & & & & & & & & 265 & 265 \\
\hline Pakistan & & & & & & 398 & 380 & 307 & 1,085 \\
\hline Portugal & & & & & & & 141 & & 141 \\
\hline Qatar & & & & 418 & & & & & 418 \\
\hline Romania & & & & & & & & 206 & 206 \\
\hline Serbia & & & & & & & 502 & & 502 \\
\hline Singapore & & & 592 & & & & 163 & & 755 \\
\hline Slovenia & & & & & 195 & 382 & & & 577 \\
\hline South Africa & & & & & & & 389 & & 389 \\
\hline South Korea & & & & & & 153 & & & 153 \\
\hline Spain & & & & & 256 & & 681 & 740 & 1,677 \\
\hline Switzerland & & & & & & & & 212 & 212 \\
\hline Taiwan & & 402 & & & 370 & & & 285 & 1,057 \\
\hline Thailand & & & & & & 382 & & & 382 \\
\hline Turkey & & & & & & & 234 & & 234 \\
\hline UK & & & & & & 398 & 523 & 214 & 1,135 \\
\hline USA & 530 & & 545 & 389 & 934 & 510 & 815 & 558 & 4,281 \\
\hline Vietnam & & & & & & & 1,159 & & 1,159 \\
\hline Total per Year & 530 & 402 & 1,534 & 1,588 & 2,568 & 5,444 & 13,733 & 9,046 & 34,845 \\
\hline
\end{tabular}

Note: highlighted countries have more influence (total sample $>2,000$ people). *Considered only the first three months of the year.

between dependent and independent variables. The Rstudio package Metafor was used for the meta-analysis. The most used dependent variables were, in descending order: behavioral intentions (19 relationships), use behavior ( 9 relations), satisfaction ( 7 relations), attitude (6 relationships), usefulness ( 5 relations), and ease of use ( 2 relationships), as indicated in Table 6. Only two of the 48 relationships did not prove to be statistically significant $(\mathrm{p}<0.01)$ when assessing confidence interval, these are the relationships between behavioral intentions and privacy risk $(r=.046)$ and usefulness and innovativeness of IT $(r=.329)$. Behavioral intention represents the principal variable, considering the number of relationships observed, correlation, and sample. Some relations with more than ten observations are highlighted as usefulness and ease of use (14 relationships, 4,925 individuals, $r=.643$ ), use behavior and behavior intentions (10 relations, 4,264 respondents, $r=.536$ ), attitude and usefulness (13 relations, sample $=4,333, r=.620$ ), and attitude and ease of use (10 relations, 4,048 individuals, $r=.547$ ), as demonstrated in Table 6.

The information presented in Table 6 denotes that attitude $(r=.627$, FSN $=129,702)$, satisfaction $(r=.625, \mathrm{FSN}=16,442)$ and compatibility $(r=.626, \mathrm{FSN}=10,641)$ are the most relevant predictors for behavioral intentions to adopt DT. For DT technologies use, behavioral intentions ( $r$ $=.536, \mathrm{FSN}=67,986)$, satisfaction $(r=.582, \mathrm{FSN}=8,233)$ and habit $(r$ $=.472, \mathrm{FSN}=14,332$ ) are the key predictors. For the weight analysis, of the 48 relationships, 25 were classified as "Best Predictors" and 13 as "Promising Predictors" for individual adoption of DT, as described in Table 6. Since the UTAUT model captures the essential elements of eight other technology adoption models (Venkatesh et al., 2003), and UTAUT2 extends the original ones with new constructs (Venkatesh et al., 2012), the combination of the meta and weight analysis allowed the design of the model shown in Figure 3. It denotes the correlation ( $r$ ) and weight among the principal variables found in this research, presenting, as in the UTAUT model, connections, possible extensions, and important outcomes for technology adoption, considering some rules like only the best and promising predictors from the weight analysis, and constructs with high correlation.

\subsection{Moderation analysis}

Considering the importance of moderators to clarify changes in the effect size of technology adoption models (Santini et al., 2019), moderation analyses were conducted at the economic, cultural, and innovation levels. Two criteria were used to select the best relations for moderation: having sufficient observations (more than 30) (Geyskens et al., 2009); and having high heterogeneity (Santini et al., 2019). Of the 48 presented relations, only three meet the criteria: behavioral intentions with the variable's usefulness ( 43 relations, $Q=1,484.09, \mathrm{I}^{2}=97.2 \%$ ), ease of use 
Table 4. Studies used in this research.

\begin{tabular}{|c|c|c|c|c|c|}
\hline ID & Reference & Model & Country & Source & Sample \\
\hline 1 & (Navaridas-Nalda et al., 2020) & TAM & Spain & JA & 142 \\
\hline 2 & (Jain et al., 2021) & TRA, TBS, TBRA & India & JA & 487 \\
\hline 3 & (Lié bana-Cabanillas et al., 2020a,b) & TAM, UTAUT & Spain & JA & 539 \\
\hline 4 & (Guggemos and Seufert, 2021) & TPB & Switzerland & JA & 212 \\
\hline 5 & (Manfreda et al., 2021) & TAM, UTAUT & Slovenia & JA & 382 \\
\hline 6 & (Jahanmir et al., 2020) & TAM, UTAUT & Portugal & JA & 141 \\
\hline 7 & (Ben Arfi et al., 2021a) & UTAUT & France & JA & 268 \\
\hline 8 & (Cabrera-Sá nchez et al., 2021) & UTAUT2 & Spain & JA & 740 \\
\hline 9 & (Nastjuk et al., 2020) & TAM & Germany & JA & 316 \\
\hline 10 & (Baudier et al., 2020) & UTAUT2, TAM2 & France & JA & 316 \\
\hline 11 & (Pillai et al., 2020) & TAM, TRI & India & JA & 1,250 \\
\hline 12 & (M. Z. Alam et al., 2020) & UTAUT2 & Bangladesh & JA & 400 \\
\hline 13 & (Rahman et al., 2016) & TPB, TAM, UTAUT & USA & JA & 314 \\
\hline 14 & (H. Li et al., 2014) & TAM, UTAUT & USA & JA & 192 \\
\hline 15 & (Huang and Chueh, 2020) & TAM, UTAUT & China & JA & 258 \\
\hline 16 & (Chandra et al., 2020) & TAM, UTAUT & Singapore & JA & 163 \\
\hline 17 & (Jetter et al., 2018) & TAM & UK and Italy & JA & 51 \\
\hline 18 & (Yan et al., 2021) & TAM, UTAUT & China & JA & 397 \\
\hline 19 & (Z. Hu et al., 2019) & TAM & China & JA & 387 \\
\hline 20 & (Meske and Junglas, 2020) & TAM, TPB & Germany & JA & 149 \\
\hline 21 & (Khoa, 2020) & TAM & Vietnam & $\mathrm{CP}$ & 918 \\
\hline 22 & (Schikofsky et al., 2020) & TAM & Germany & JA & 1,067 \\
\hline 23 & (Chakraborty et al., 2020) & TAM & India & JA & 253 \\
\hline 24 & (Chakraborty et al., 2021) & TAM, TPB & India & JA & 146 \\
\hline 25 & (Scott et al., 2019) & TAM & UK and USA* & JA & 201 \\
\hline 26 & (S. C. Chen et al., 2018) & TAM, ECM, DOI & Taiwan & JA & 370 \\
\hline 27 & (Y. Chen et al., 2018) & TAM, ELM & China & JA & 284 \\
\hline 28 & (Rodger, 2014) & TAM & USA & JA & 338 \\
\hline 29 & (Rahi et al., 2019) & UTAUT & Pakistan & JA & 398 \\
\hline 30 & (Queiroz and Fosso Wamba, 2019) & TAM, UTAUT & India and USA* & JA & 738 \\
\hline 31 & (Kamolsook et al., 2019) & UTAUT & Thailand & JA & 382 \\
\hline 32 & (Schmidthuber et al., 2020) & TAM, UTAUT & Austria & JA & 670 \\
\hline 33 & (Chopdar et al., 2018) & UTAUT2 & India and USA* & JA & 366 \\
\hline 34 & (Lau et al., 2021) & TAM & Malaysia & JA & 330 \\
\hline 35 & (Bölen, 2020) & TAM, DOI & Turkey & JA & 234 \\
\hline 36 & (Martínez-Caro et al., 2018) & TAM, D\&M & Spain & JA & 256 \\
\hline 37 & (Pillet and Carillo, 2016) & UTAUT, TAM & France and Poland & JA & 66 \\
\hline 38 & (So et al., 2018) & TPB, TAM, UTAUT2 & USA & JA & 519 \\
\hline 39 & (Liébana-Cabanillas et al., 2020a,b) & TAM, UTAUT & India & JA & 206 \\
\hline 40 & (Pham and Ho, 2015) & TAM, DOI & Taiwan & JA & 402 \\
\hline 41 & (Aswani et al., 2018) & UTAUT2 & India & $\mathrm{CP}$ & 257 \\
\hline 42 & (Hao et al., 2017) & TAM, UTAUT & China & JA & 292 \\
\hline 43 & (Teo et al., 2016) & TPB, UTAUT & Singapore & JA & 592 \\
\hline 44 & (El-Masri and Tarhini, 2017) & TAM, UTAUT2 & USA and Qatar* & JA & 807 \\
\hline 45 & (Lin et al., 2021) & TAM & Taiwan & JA & 285 \\
\hline 46 & (Udo et al., 2016) & UTAUT, NAM & India and USA* & JA & 562 \\
\hline 47 & (Kummer et al., 2017) & TAM, UTAUT & Australia and Germany* & JA & 489 \\
\hline 48 & (Balakrishnan and Shuib, 2021) & UTAUT, TRI & Malaysia & JA & 258 \\
\hline 49 & (Nikou et al., 2020) & TAM, UTAUT & Netherlands & JA & 624 \\
\hline 50 & (M. M. D. Alam et al., 2021) & UTAUT2 & Bangladesh & JA & 434 \\
\hline 51 & (Park et al., 2019) & TAM & South Korea & JA & 153 \\
\hline 52 & (Vimalkumar et al., 2021) & UTAUT2 & India & JA & 252 \\
\hline 53 & (Gupta et al., 2020) & UTAUT, ECM & India & JA & 716 \\
\hline 54 & (A. Pal et al., 2020) & UTAUT, ECM & India & JA & 298 \\
\hline 55 & (Patil et al., 2020) & TAM, UTAUT & India & JA & 491 \\
\hline 56 & (Mariani et al., 2021) & TAM & UK & JA & 214 \\
\hline 57 & (Rafique et al., 2021) & TAM, ECM & Pakistan & JA & 307 \\
\hline 58 & (Ray et al., 2019) & TAM, SCT & India & JA & 513 \\
\hline
\end{tabular}


Table 4 (continued)

\begin{tabular}{|c|c|c|c|c|c|}
\hline ID & Reference & Model & Country & Source & Sample \\
\hline 59 & (Milanović et al., 2020) & UTAUT & Serbia & JA & 502 \\
\hline 60 & (Saheb, 2020) & TAM, DOI & Iran & JA & 582 \\
\hline 61 & (Kunz and Santomier, 2019) & UTAUT2 & Germany & JA & 570 \\
\hline 62 & (Kar et al., 2021) & TAM, UTAUT & India & JA & 685 \\
\hline 63 & (Kabir, 2020) & TAM, SDT & Bangladesh & JA & 215 \\
\hline 64 & (G. Hu et al., 2020) & TAM, UTAUT & Pakistan & JA & 380 \\
\hline 65 & (Albashrawi and Motiwalla, 2020) & UTAUT, D\&M & USA & JA & 472 \\
\hline 66 & (Hajiheydari et al., 2021) & TAM, UTAUT & Iran & JA & 427 \\
\hline 67 & (D. Pal and Patra, 2021) & TAM, TTF & India & JA & 232 \\
\hline 68 & (Nguyen et al., 2020) & UTAUT2 & Vietnam & JA & 241 \\
\hline 69 & (Meng et al., 2019) & TAM, TTF & India & JA & 270 \\
\hline 70 & (Ben Arfi et al., 2021b) & UTAUT & France & JA & 267 \\
\hline 71 & (Delgosha and Hajiheydari, 2020) & TAM, UTAUT & UK & JA & 523 \\
\hline 72 & (Johnson et al., 2018) & TAM, DOI & USA & JA & 270 \\
\hline 73 & (Sun et al., 2020) & TAM, UTAUT & China & JA & 401 \\
\hline 74 & (Jaklič et al., 2018) & TAM, UTAUT & Slovenia & JA & 195 \\
\hline 75 & (Thakurta et al., 2020) & TAM, UTAUT & Germany and India* & JA & 278 \\
\hline 76 & (Alarabiat et al., 2021) & TAM, UTAUT, TPB & Jordan & JA & 400 \\
\hline 77 & (Çera et al., 2020) & TAM, UTAUT2 & Albania & JA & 380 \\
\hline 78 & (Sobti, 2019) & UTAUT & India & JA & 640 \\
\hline 79 & (Khan et al., 2020) & TAM, SCT & China & JA & 353 \\
\hline 80 & (Mamonov and Benbunan-Fich, 2020) & TAM, UTAUT & USA & JA & 558 \\
\hline 81 & (P. C. Li et al., 2020) & UTAUT, TTF & China & $\mathrm{CP}$ & 168 \\
\hline 82 & (He et al., 2020) & UTAUT, TPB & Belgium & JA & 202 \\
\hline 83 & (Netshirando et al., 2020) & TAM, UTAUT2 & South Africa & JA & 389 \\
\hline 84 & (Khaksar et al., 2021) & TAM, DOI & Australia & JA & 302 \\
\hline 85 & (Taghizadeh et al., 2021) & UTAUT, DOI, ECM & Bangladesh, Malaysia, Oman, Romania, and Iran** & JA & 1,193 \\
\hline 86 & (Aldossari and Sidorova, 2020) & UTAUT2 & USA & JA & 343 \\
\hline 87 & (Hujran et al., 2020) & TAM, UTAUT2, TPB & Jordan & JA & 302 \\
\hline 88 & (El-Haddadeh et al., 2019) & TAM, UTAUT & UK & JA & 313 \\
\hline
\end{tabular}

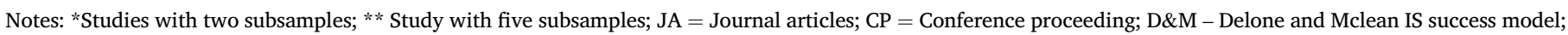

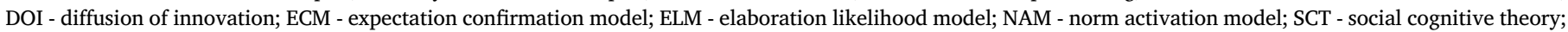

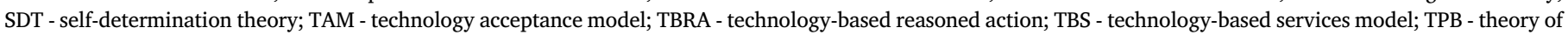

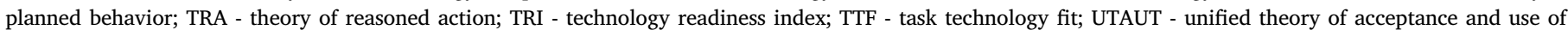
technology.

(30 relations, $\mathrm{Q}=862.60, \mathrm{I}^{2}=96.8 \%$ ), and social influence ( 35 relations, $\mathrm{Q}=776.02, \mathrm{I}^{2}=95.6 \%$ ). As no consistent results were found among behavioral intentions and social influence, the moderation test results are only presented for the first two relations.

At an economic level, the GDP had no significant moderation effect on the relationships between behavioral intentions and usefulness $(\beta=.599$, Mlow $=.553$, Mhigh $=.506)$ or ease of use $(\beta=.409$, Mlow $=.381$, Mhigh $=.373$ ). Apropos innovation indicators, positive moderation effects were found for human capital and the research dimension between behavioral intentions and ease of use $(\beta=.336$, Mlow $=.438$, Mhigh $=.309, \mathrm{p}<$ 0.10 ), and for knowledge $\&$ technology outputs on both relations among

Table 5. Respondents grouped by technology.

\begin{tabular}{lll}
\hline Technology Type & Respondents & $(\%)$ \\
\hline Blockchain & 953 & $3 \%$ \\
Healthcare Technology & 1,332 & $4 \%$ \\
Social Technology & 1,671 & $5 \%$ \\
Educational Technology & 1,749 & $5 \%$ \\
Internet of things & 2,279 & $6 \%$ \\
Artificial Intelligence & 3,224 & $9 \%$ \\
Digital services-systems & 3,596 & $10 \%$ \\
Mobile & 20,041 & $58 \%$ \\
Total & 34,845 & \\
\hline
\end{tabular}

behavioral intentions and usefulness $(\beta=.581$, Mlow $=.613$, Mhigh $=$ $.498, \mathrm{p}<0.10)$ and ease of use $(\beta=.363$, Mlow $=.453$, Mhigh $=.334, \mathrm{p}<$ $0.05)$. No significant moderating effect was identified for the remaining dimensions (institutions, infrastructure, market sophistication, and creative outputs). A significant moderating effect respecting the cultural context was found for individualism, on the relation among behavioral intentions and ease of use $(\beta=.355$, Mlow $=.444$, Mhigh $=.327, \mathrm{p}<$ $0.05)$. No significant moderating effects were found for the other factors (power distance, masculinity, and uncertainty avoidance). All results are described in Table 7.

\section{Discussion}

The global health crisis has maximized the distinct role attributed to information technology in innovative solutions for real-time communication and connectivity (Coccia, 2020). The technological advance brought about by the pandemic context accelerated service digitization and product transformation, creating the opportunity from a quantitative view for a DT update to present main factors related to individual technology adoption. By consolidating theoretical models and empirical data from previous publications, this literature review raises 442 relations important to DT between independent and dependent variables, synthesized into 48 statistically relevant relationships. To the best of our knowledge, this is the first investigation to run a meta and weight analysis correlating individual adoption and DT. The meta-analysis 


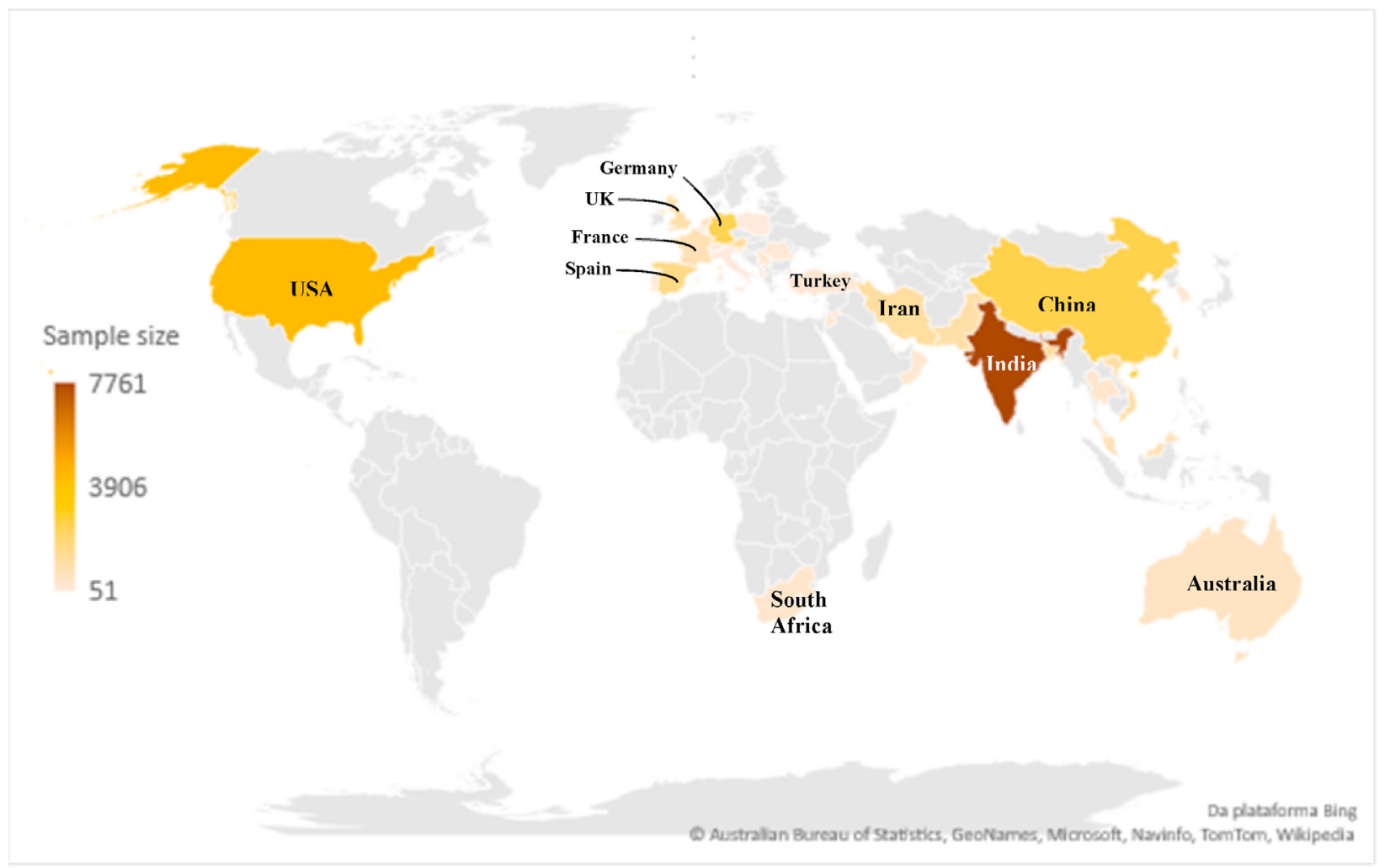

Figure 2. Respondents' distribution by country.

results show that 46 of the 48 relationships presented are statistically significant, as the relations between behavioral intention to privacy risk and usefulness to the innovativeness of IT are considered insignificant for the research. Of the six dependent constructs identified, four are included in TAM and UTAUT (usefulness, ease of use, behavioral intentions, and use behavior), indicated as most used in adoption research (Venkatesh et al., 2003). Regarding the other dependent variables, attitude emerges from TRA and TPB, while satisfaction arises from the IS success model by DeLone and McLean (1992).

Our results consolidate the validity of the primary relationships of TAM, UTAUT, and UTAUT2 models for individual adoption of DT, harmonizing apparent inconsistencies pointed out in the existing literature and bringing up a new relationship between usefulness and use behavior. The impact of social influence and facilitating conditions on DT intention and use is noteworthy. Treated as contingent variables by technology adoption theory, the presented results corroborate the importance of considering not only the technological aspects of transformation (Verhoef et al., 2021) but also the strength of social relations and peer pressure (Meske and Junglas, 2020) in addition to organizational environment and infrastructure supporting disruptive technology adoption and use (Navaridas-Nalda et al., 2020). These findings are convergent with recent bibliographic reviews on DT (Kraus et al., 2021; Mergel et al., 2019; Nadkarni and Prügl, 2021; Verhoef et al., 2021; Vial, 2019).

Moreover, the findings affirm the results of DT research applied in areas such as healthcare (Alam et al., 2020; Rodger, 2014; Yan et al., 2021), education (Navaridas-Nalda et al., 2020; Taghizadeh et al., 2021), digital services (Jain et al., 2021; Jaklič et al., 2018; Thakurta et al., 2020), blockchain (Queiroz and Fosso Wamba, 2019), Internet of Things (Aldossari and Sidorova, 2020), and artificial intelligence (Cabrera-Sá nchez et al., 2021).

Nevertheless, Scott et al. (2019) found unsatisfactory results among social influence and behavioral intentions in accessing digital services, and (Ben Arfi et al., 2021a) discovered negative effects between behavioral intention to social influence and facilitating conditions in healthcare. Usefulness and ease of use arouse particular attention since they appear as independent constructs in almost all other variables in addition to being dependent variables. It denotes the need for customization and essential characteristics like usability, utility, user experience, and ease of learning (Venkatesh et al., 2003, 2012) for DT adoption, convergent with previous studies (Baudier et al., 2020; Chopdar et al., 2018; Kamolsook et al., 2019; Khaksar et al., 2021; Pillai et al., 2020). Similar to the findings, a recent study by Aparicio et al. (2021) shows that usefulness and ease of use are determinants of the e-commerce platforms' use intentions. Contrarily, negative results were found between behavioral intentions to ease of use (Çera et al., 2020) and usefulness (Sobti, 2019).

Of the relationships presented, the top eight with the strongest correlation ( $r$ ), all above the 0.660 limit, are (i) satisfaction with the variable's confirmation (.778), compatibility (.738), complexity (.684), usefulness (.678), and hedonic motivation (.660); (ii) behavioral intentions with perceived value (.735); (iii) attitude related to social influence (.698); and (iv) ease of use with trust (.661). Regarding the importance of satisfaction and usefulness for intentions to use, convergent results were found in the study of (Franque et al., 2021) in the mobile payment subject. Used to measure business value creation during different phases of DT (Verhoef et al., 2021), satisfaction alongside responsiveness and business scope are key strategic outcomes for DT (Cha et al., 2015). Estimated precision from the $95 \%$ confidence interval shows that some effect sizes are more accurate than others. As an example of greater precision of average effect (Borenstein et al., 2009), we cite usefulness to ease of use (.637-.669), satisfaction to hedonic motivation (.626-.691), behavioral intentions to facilitating conditions (.460-.553), and behavioral intentions to risk (.241-.341), all with narrow variation up to 100 , indicating relationship robustness. Conversely, examples of less accurate estimates, with wide variations up to 700, are seen between usefulness to compatibility (.135-.840), satisfaction to ease of use (.216-.834), use behavior to trust (.023-.562), and usefulness to 
Table 6. Meta and weight analysis results.

\begin{tabular}{|c|c|c|c|c|c|c|c|c|c|c|c|c|c|c|}
\hline \multirow{2}{*}{$\begin{array}{l}\text { Independent } \\
\text { Constructs }\end{array}$} & \multirow{2}{*}{$\begin{array}{l}\text { Dependent } \\
\text { Constructs }\end{array}$} & \multirow[t]{2}{*}{ Relations } & \multirow[t]{2}{*}{ Samples } & \multicolumn{7}{|c|}{ Meta-Analysis } & \multicolumn{4}{|c|}{ Weight Analysis } \\
\hline & & & & $r$ & $95 \% \mathrm{Cl}$ & & $\mathrm{Q}$ & $\mathrm{I}^{2}$ & FSN & $\begin{array}{l}\text { Egger's } \\
\text { Intercept }\end{array}$ & NonSig & Sig & Weight & Type \\
\hline Usefulness & \multirow{19}{*}{$\begin{array}{l}\text { Behavioral } \\
\text { intention }\end{array}$} & 43 & 18,116 & .559 & .495 & .616 & $1,484.09^{*}$ & $97.2 \%$ & $1,107,360$ & .837 & 5 & 38 & .884 & BP \\
\hline Social influence & & 35 & 14,056 & .410 & .341 & .474 & $776.02 *$ & $95.6 \%$ & 644,268 & .440 & 7 & 28 & .800 & BP \\
\hline Ease of use & & 30 & 13,228 & .408 & .324 & .486 & $862.60 *$ & $96.8 \%$ & 435,439 & .538 & 6 & 24 & .800 & BP \\
\hline $\begin{array}{l}\text { Facilitating } \\
\text { conditions }\end{array}$ & & 22 & 8,135 & .462 & .460 & .553 & $659.23^{*}$ & $96.8 \%$ & 181,818 & .041 & 3 & 19 & .864 & BP \\
\hline Risk & & 21 & 6,797 & .292 & .241 & .341 & $100.86^{*}$ & $80.2 \%$ & 385,039 & .863 & 7 & 14 & .667 & \\
\hline Attitude & & 19 & 6,398 & .627 & .519 & .715 & $740.59 *$ & $97.6 \%$ & 129,702 & .385 & 0 & 19 & 1 & $\mathrm{BP}$ \\
\hline Hedonic motivation & & 14 & 7,599 & .571 & .403 & .701 & $1,035.81 *$ & $98.7 \%$ & 50,642 & .422 & 0 & 14 & 1 & BP \\
\hline Trust & & 14 & 4,847 & .492 & .372 & .595 & $350.37^{*}$ & $96.3 \%$ & 74,159 & .109 & 2 & 12 & .857 & BP \\
\hline Price value & & 13 & 4,675 & .271 & .179 & .359 & 133.99* & $91.0 \%$ & 29,619 & .072 & 1 & 12 & .923 & BP \\
\hline Habit & & 12 & 4,624 & .485 & .291 & .641 & $684.85^{*}$ & $98.4 \%$ & 28,934 & .212 & 3 & 9 & .750 & \\
\hline Privacy risk & & 11 & 3,627 & .046 & .150 & .240 & $361.27^{*}$ & $97.2 \%$ & 29 & .300 & 3 & 8 & .727 & \\
\hline Self-efficacy & & 8 & 2,715 & .335 & .073 & .553 & $433.91^{*}$ & $98.2 \%$ & 2,211 & .570 & 3 & 5 & .625 & \\
\hline $\begin{array}{l}\text { Perceived behavioral } \\
\text { control }\end{array}$ & & 7 & 1,837 & .371 & .194 & .525 & $97.36^{*}$ & $93.8 \%$ & 18,501 & .043 & 0 & 7 & 1 & BP \\
\hline Satisfaction & & 6 & 2,203 & .625 & .449 & .755 & $169.74 *$ & $97.1 \%$ & 16,442 & .583 & 0 & 6 & 1 & BP \\
\hline Relative advantage & & 5 & 1,194 & .468 & .171 & .687 & $115.23^{*}$ & $96.5 \%$ & 2,833 & .248 & 0 & 5 & 1 & BP \\
\hline Compatibility & & 5 & 2,253 & .626 & .526 & .709 & $40.27^{*}$ & $91.1 \%$ & 10,641 & .028 & 0 & 5 & 1 & $\mathrm{BP}$ \\
\hline $\begin{array}{l}\text { Personal } \\
\text { innovativeness }\end{array}$ & & 4 & 2,341 & .409 & .321 & .491 & $18.36^{*}$ & $83.7 \%$ & 21,592 & .709 & 0 & 4 & 1 & PP \\
\hline Perceived costs & & 4 & 1,880 & .264 & .048 & .456 & 66.81 & $95.5 \%$ & 4,591 & .350 & 1 & 3 & .750 & \\
\hline Perceived value & & 3 & 1,484 & .735 & .596 & .831 & $36.62^{*}$ & $94.5 \%$ & 4,079 & .074 & 0 & 3 & 1 & PP \\
\hline Behavior intentions & \multirow[t]{9}{*}{ Use Behavior } & 10 & 4,264 & .536 & .417 & .637 & $232.04^{*}$ & $96.1 \%$ & 67,986 & .749 & 0 & 10 & 1 & BP \\
\hline $\begin{array}{l}\text { Facilitating } \\
\text { conditions }\end{array}$ & & 9 & 3,136 & .321 & .194 & .438 & $116.92 *$ & $93.2 \%$ & 31,531 & .294 & 3 & 6 & .667 & \\
\hline Satisfaction & & 8 & 2,373 & .582 & .366 & .739 & $335.84 *$ & $97.9 \%$ & 8,233 & .025 & 0 & 8 & 1 & BP \\
\hline Habit & & 8 & 2,860 & .472 & .288 & .622 & $232.46^{*}$ & $97.0 \%$ & 14,332 & .157 & 0 & 8 & 1 & BP \\
\hline Risk & & 6 & 1,251 & .319 & .202 & .426 & $24.72^{*}$ & $79.8 \%$ & 10,957 & .331 & 1 & 5 & .833 & BP \\
\hline Self-quarantine & & 6 & 1,627 & .257 & .022 & .466 & $119.61 *$ & $95.8 \%$ & 8,392 & .085 & 2 & 4 & .667 & \\
\hline Privacy risk & & 5 & 1,989 & .274 & .049 & .472 & $110.68^{*}$ & $96.4 \%$ & 2,932 & .623 & 0 & 5 & 1 & BP \\
\hline Trust & & 4 & 1,344 & .318 & .023 & .562 & $96.45^{*}$ & $96.9 \%$ & 1,970 & .979 & 1 & 3 & .750 & \\
\hline Usefulness & & 3 & 1,030 & .472 & .261 & .640 & $30.39^{*}$ & $93.4 \%$ & 5,536 & .291 & 0 & 3 & 1 & PP \\
\hline Confirmation & \multirow[t]{7}{*}{ Satisfaction } & 8 & 2,586 & .778 & .673 & .853 & $228.27^{*}$ & $96.9 \%$ & 16,900 & .953 & 0 & 8 & 1 & BP \\
\hline $\begin{array}{l}\text { Facilitating } \\
\text { conditions }\end{array}$ & & 6 & 1,665 & .632 & .482 & .746 & $100.47^{*}$ & $95.0 \%$ & 12,018 & .079 & 2 & 4 & .667 & \\
\hline Compatibility & & 6 & 1,563 & .738 & .624 & .820 & $90.68^{*}$ & $94.5 \%$ & 6,615 & .044 & 1 & 5 & .833 & BP \\
\hline Hedonic motivation & & 5 & 1,193 & .660 & .626 & .691 & 3.89 & $0.0 \%$ & 5,079 & .195 & 0 & 5 & 1 & BP \\
\hline Complexity & & 5 & 1,193 & .684 & .625 & .736 & $13.20^{*}$ & $69.7 \%$ & 4,778 & .630 & 1 & 4 & .800 & BP \\
\hline Ease of use & & 4 & 1,332 & .611 & .216 & .834 & $246.82^{*}$ & $98.8 \%$ & 2,847 & .600 & 0 & 4 & 1 & PP \\
\hline Usefulness & & 4 & 1,495 & .678 & .557 & .771 & $44.53^{*}$ & $93.3 \%$ & 5,100 & .913 & 0 & 4 & 1 & PP \\
\hline Usefulness & \multirow[t]{6}{*}{ Attitude } & 13 & 4,333 & .620 & .504 & .714 & $376.07^{*}$ & $96.7 \%$ & 44,804 & .144 & 0 & 13 & 1 & BP \\
\hline Ease of use & & 10 & 4,048 & .547 & .436 & .642 & $164.85^{*}$ & $94.5 \%$ & 31,434 & .117 & 0 & 10 & 1 & BP \\
\hline Hedonic motivation & & 5 & 1,535 & .586 & .359 & .748 & 132.91 * & $97.0 \%$ & 9,628 & .261 & 0 & 5 & 1 & BP \\
\hline Privacy Risk & & 3 & 973 & .295 & .130 & .444 & $15.15^{*}$ & $86.8 \%$ & 3,505 & .087 & 1 & 2 & .667 & \\
\hline Social influence & & 3 & 1,178 & .698 & .496 & .828 & $60.27^{*}$ & $96.7 \%$ & 3,006 & .809 & 0 & 3 & 1 & PP \\
\hline Trust & & 3 & 1,221 & .586 & .468 & .684 & $16.70^{*}$ & $88.1 \%$ & 4,080 & .226 & 0 & 3 & 1 & PP \\
\hline Ease of use & \multirow[t]{5}{*}{ Usefulness } & 14 & 4,925 & .643 & .637 & .669 & $176.92^{*}$ & $92.7 \%$ & 63,021 & .496 & 0 & 14 & 1 & BP \\
\hline Social influence & & 3 & 893 & .280 & .038 & .491 & $28.61^{*}$ & $93.0 \%$ & 99 & .224 & 0 & 3 & 1 & PP \\
\hline Innovativeness of IT & & 3 & 2,374 & .329 & -.355 & .784 & $530.59^{*}$ & $99.6 \%$ & 486 & .808 & 0 & 3 & 1 & $P P$ \\
\hline Compatibility & & 3 & 988 & .591 & .135 & .840 & $150.07^{*}$ & $98.7 \%$ & 1,653 & .456 & 0 & 3 & 1 & PP \\
\hline Confirmation & & 3 & 1,393 & .531 & .212 & .747 & $93.97^{*}$ & $97.9 \%$ & 1,145 & .993 & 0 & 3 & 1 & PP \\
\hline Innovativeness of IT & \multirow[t]{2}{*}{ Ease of Use } & 3 & 2,460 & .392 & .192 & .561 & $54.21 *$ & $96.3 \%$ & 8,228 & .673 & 0 & 3 & 1 & PP \\
\hline Trust & & 3 & 796 & .661 & .490 & .782 & $26.80^{*}$ & $92.5 \%$ & 2,231 & .844 & 0 & 3 & 1 & PP \\
\hline
\end{tabular}

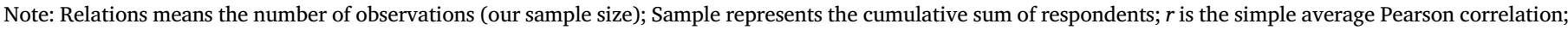

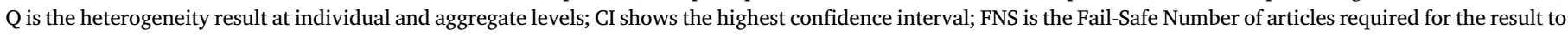

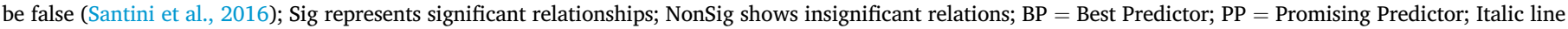
represents not supported relationship given low correlation or confidence interval difference. 


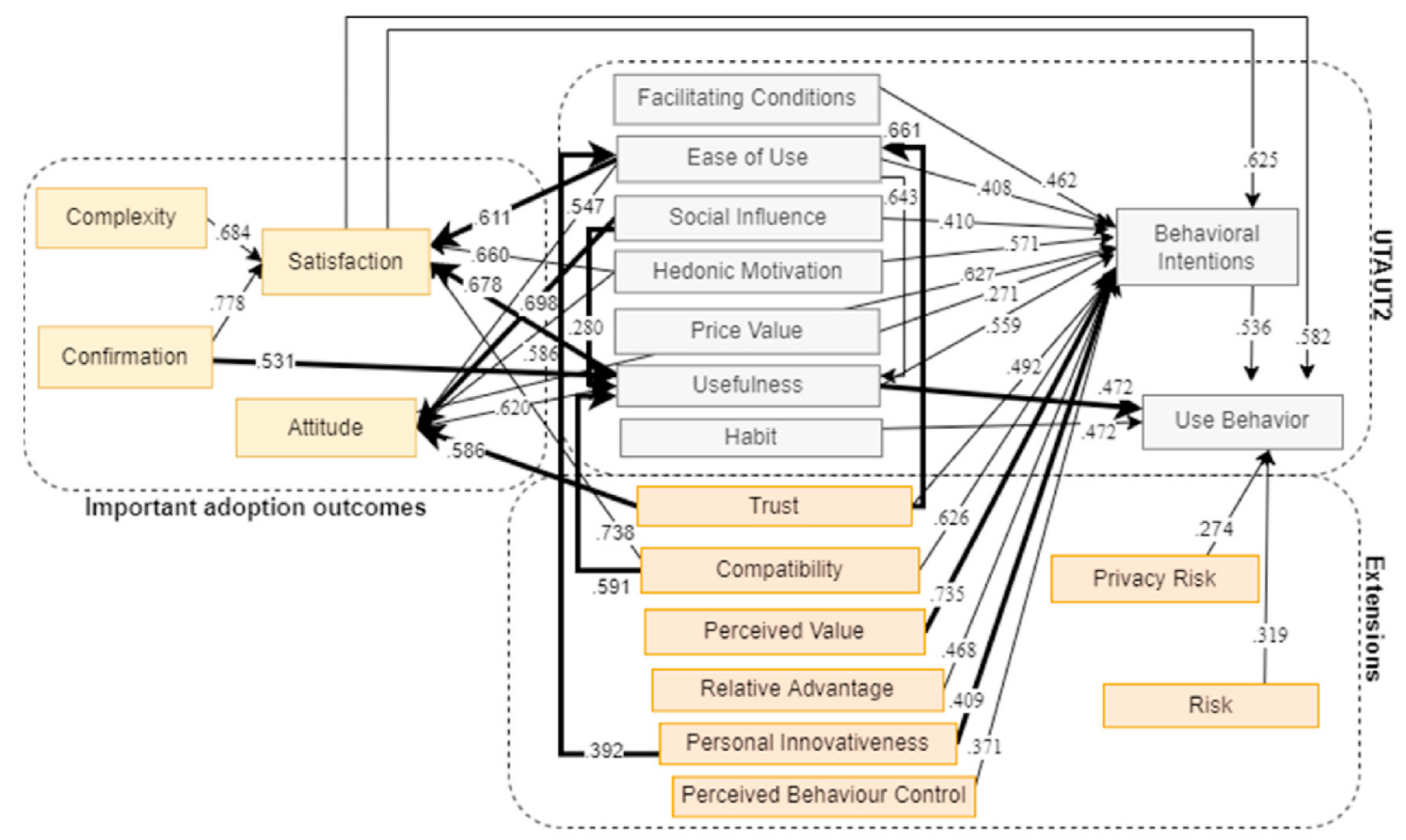

Notes: a) numerical values represent the average $\mathrm{r}$ with $\mathrm{p}<0.01$; b) bold arrows represent promising predictors.

Figure 3. Proposed UTAUT - UTAUT2 model, with other important adoption outcomes and extensions after weight and meta-analysis.

confirmation (.212-.747), denoting weak connections (Borenstein et al., 2009).

Relevant results were found for cultural moderators, as high individualism strengthens the relationship between ease of use and behavioral intentions. A digital culture driven by DT can be the key to these findings, empowering the individual as an autonomous body responsible for building their own will (Guy, 2019). Individualistic people will strive harder to learn new technologies (Blut et al., 2021) as they think more about themselves as a path to self-fulfillment and personal success, demonstrating social competence according to high standards of reference (Veiga et al., 2001). Otherwise, collectivist cultures do not have a reference for success, devaluing the individual fluency of IT to keep bonds and prestige with colleagues, leading individuals who are more intellectually equipped to hide their knowledge (Veiga et al., 2001). Given that DT is linked to introducing new technology, bringing changes and resistance in collectivist cultures, it favors the individualistic context with the need for better usability (Harrati et al., 2016; Hofstede, 2001). No moderating effect was found in the tested relations for the remaining cultural factors such as power distance, masculinity, and uncertainty avoidance. Recognizing that our results may have been influenced by the large volume of studies about mobile applications for DT, the findings are convergent with Blut et al. (2021), as the effects of usefulness and ease of use on behavioral intentions and use are more substantial for mobile users.

The most significant moderation result came from innovation indicators. Knowledge and technology outputs represent intellectual capital and strengthen both relationships of behavioral intentions (usefulness and ease of use), comprising as sub-pillars knowledge creation, the impact of innovations at the micro and macroeconomic level, and knowledge absorption (WIPO, 2020). The results show that countries with high intellectual capital scores have higher readiness levels for DT and system adoption (Švarc et al., 2020). The knowledge-free environment brought by intellectual capital provides innovation and raises the standard for creating new products (Švarc et al., 2020), being responsible for DT market expansion, faced by the pressure for better usability and utility required by high-quality applications (Ståhle et al., 2015). Reflecting the pattern of education and innovation in some economies, human capital and research impact the relation among intentions and ease of use, being composed by the quality of R\&D activities, elementary, secondary, and higher education (WIPO, 2020). Contexts with immense human capital reflect ample quality education, demanding high standards for disruptive technology solutions, such as the quality of personal skills and professional training positively impacts national readiness for DT (Švarc et al., 2020). Well-educated individuals strengthen the relationship between ease of use and behavioral intentions in the context of technology adoption (Baudier et al., 2020; Sobti, 2019). No relevant moderation results were seen for the remaining innovation indicators, as Table 7 exemplifies. Moderation by GDP had no relevant effect, similarly to (Franque et al., 2020). However, the importance of this moderator for DT adoption suggests that further studies are imperative to consider that countries with high economic development tend to have better technology adoption (Kim and Peterson, 2017).

A major finding of this research is to have satisfaction as the most relevant outcome for DT, because in addition to being the construct that has the highest correlations, it is the only dependent variable in which the correlation $(\beta)$ is greater than .610 in all significant relationships with the independent variables, which are: confirmation (0.778), compatibility (0.738), complexity (0.684), usefulness (0.678), hedonic motivation (0.660), facilitating conditions (0.632), and ease of use (0.611).

The result of weight and meta-analysis made it possible to assess the statistical significance and select the central relationships between variables (Blut et al., 2021), indicating the most relevant factors for the adoption of DT and making it possible to see the predictive power of the variables satisfaction and attitude, not considered in the two main models of TAM and UTAUT. In this context, it was possible to propose a new theoretical model capable of benefiting future research on DT, focusing on different outcomes of intention and use of technology, as shown in Figure 4. The construction of the presented model followed the criteria: (i) statistically significant relationships through the 
Table 7. Moderation analysis.

\begin{tabular}{|c|c|c|c|c|c|c|c|}
\hline \multirow[t]{2}{*}{ Moderator level } & & \multicolumn{3}{|c|}{ Behavioral intentions to usefulness } & \multicolumn{3}{|c|}{ Behavioral intentions to ease of use } \\
\hline & & $\beta$ & $R$ & $p$ value & $\beta$ & $R$ & $p$ value \\
\hline \multirow[t]{3}{*}{ Sample size } & Intercept & & & 0.001 & & & 0.001 \\
\hline & High & 1 & & & 1 & & \\
\hline & Low & & & & & & \\
\hline \multirow[t]{3}{*}{ Institutions (political, regulatory and business environment) } & Intercept & 0.605 & & 0.001 & 0.409 & & 0.001 \\
\hline & High & 1 & 0.516 & & 1 & 0.357 & \\
\hline & Low & 0.095 & 0.567 & 0.328 & 0.082 & 0.426 & 0.451 \\
\hline \multirow[t]{3}{*}{ Human capital and research (education, tertiary education, R\&D) } & Intercept & 0.587 & & 0.001 & 0.336 & & 0.001 \\
\hline & High & 1 & 0.500 & & 1 & 0.309 & \\
\hline & Low & 0.096 & 0.565 & 0.293 & 0.189 & 0.438 & $0.055^{*}$ \\
\hline \multirow[t]{3}{*}{ Infrastructure (ICTs, general infrastructure, ecological sustainability) } & Intercept & 0.638 & & 0.001 & 0.411 & & 0.001 \\
\hline & High & 1 & 0.533 & & 1 & 0.361 & \\
\hline & Low & 0.019 & 0.525 & 0.843 & 0.050 & 0.396 & 0.622 \\
\hline \multirow[t]{3}{*}{ Market sophistication (credit, investment, trade, competition, market scale) } & Intercept & 0.592 & & 0.001 & 0.359 & & 0.001 \\
\hline & High & 1 & 0.501 & & 1 & 0.326 & \\
\hline & Low & 0.080 & 0.561 & 0.379 & 0.145 & 0.423 & 0.146 \\
\hline \multirow[t]{3}{*}{ Business sophistication (knowledge workers, innovation linkages, knowledge absorption) } & Intercept & 0.642 & & 0.001 & 0.409 & & 0.001 \\
\hline & High & 1 & 0.539 & & 1 & 0.371 & \\
\hline & Low & 0.021 & 0.521 & 0.815 & 0.046 & 0.383 & 0.654 \\
\hline \multirow[t]{3}{*}{ Knowledge \& Technology outputs (k-creation, k-impact, k-diffusion) } & Intercept & 0.581 & & 0.001 & 0.363 & & 0.001 \\
\hline & High & 1 & 0.498 & & 1 & 0.334 & \\
\hline & Low & 0.177 & 0.613 & $0.064^{*}$ & 0.206 & 0.453 & $0.038 * *$ \\
\hline \multirow[t]{3}{*}{ Creative outputs (intangible assets, creative good and services, online creativity) } & Intercept & 0.606 & & 0.001 & 0.361 & & 0.001 \\
\hline & High & 1 & 0.514 & & 1 & 0.329 & \\
\hline & Low & 0.060 & 0.553 & 0.514 & 0.151 & 0.426 & 0.130 \\
\hline \multirow[t]{3}{*}{ Power Distance } & Intercept & 0.625 & & 0.001 & 0.469 & & 0.001 \\
\hline & High & 1 & 0.523 & & 1 & 0.401 & \\
\hline & Low & 0.015 & 0.541 & 0.866 & 0.098 & 0.332 & 0.359 \\
\hline \multirow[t]{3}{*}{ Individualism } & Intercept & 0.592 & & 0.001 & 0.355 & & 0.001 \\
\hline & High & 1 & 0.510 & & 1 & 0.327 & \\
\hline & Low & 0.099 & 0.562 & 0.265 & 0.191 & 0.444 & $0.046 * *$ \\
\hline \multirow[t]{3}{*}{ Masculinity } & Intercept & 0.641 & & 0.001 & 0.417 & & 0.001 \\
\hline & High & 1 & 0.541 & & 1 & 0.382 & \\
\hline & Low & 0.025 & 0.514 & 0.787 & 0.038 & 0.373 & 0.711 \\
\hline \multirow[t]{3}{*}{ Uncertainty Avoidance } & Intercept & 0.609 & & 0.001 & 0.393 & & 0.001 \\
\hline & High & 1 & 0.518 & & 1 & 0.341 & \\
\hline & Low & 0.058 & 0.549 & 0.537 & 0.107 & 0.441 & 0.308 \\
\hline \multirow[t]{3}{*}{ Gross domestic product } & Intercept & 0.599 & & 0.001 & 0.409 & & 0.001 \\
\hline & High & 1 & 0.506 & & 1 & 0.373 & \\
\hline & Low & 0.063 & 0.553 & 0.486 & 0.045 & 0.381 & 0.655 \\
\hline
\end{tabular}

Note: ${ }^{* * *} \mathrm{p}<0.01 ; * * \mathrm{p}<0.05 ;{ }^{*} \mathrm{p}<0.10$

meta-analysis, and (ii) only relationships classified as best and promising predictors, according to weight analysis.

The model brings satisfaction and attitude as primary outcomes, also considering the relevance of two other critical variables for adopting DT, common to the TAM and UTAUT models (Venkatesh et al., 2003), which are usefulness and ease of use. All variables included have a broad theoretical basis, proven by the large number of studies that use them (Venkatesh et al., 2012), providing reliability and solidity to the use of the model in future research on DT.

Even not being considered the best predictor by weight analysis, given the lack of only one statistically relevant relationship, the facilitating conditions construct was kept in the model due to its great importance for DT. Representing the company's support and resources (Venkatesh et al., 2003), available for the adoption of DT, facilitating conditions brings the contingent factor of culture and organizational context to the complex equation (Vial, 2019), expanding the scarce debates about the ideal structure for the success of DT strategies (Verhoef et al., 2021).

\subsection{Impacts on research and practice}

This weight and meta-analysis synthesize the most relevant previous publications on DT individual adoption, drawing an overview of the subject and presenting new practical and theoretical ideas, advancing the research area. For theoretical advances, predictors of DT are clarified, following technology adoption theory, to present a UTAUT model extension, with new consolidated constructs and different outcomes for future investigations, such as satisfaction and attitude (Blut et al., 2021).

Convergent to the weight and meta-analysis conducted by Franque et al. (2020), amidst the most used factors, our results present a new UTAUT 2 model with extensions proper to the DT context, as shown in Figure 3. We also suggest, more broadly, a comprehensive model as Figure 4 indicates, which considers best and promising predictors, by mixing a comprehensive variety of constructs, from different technology adoption theories, capable of integrating the context of disruptive technologies, significantly impacting the individual adoption of DT technologies, namely the technology acceptance model (Davis, 1989), IS success 


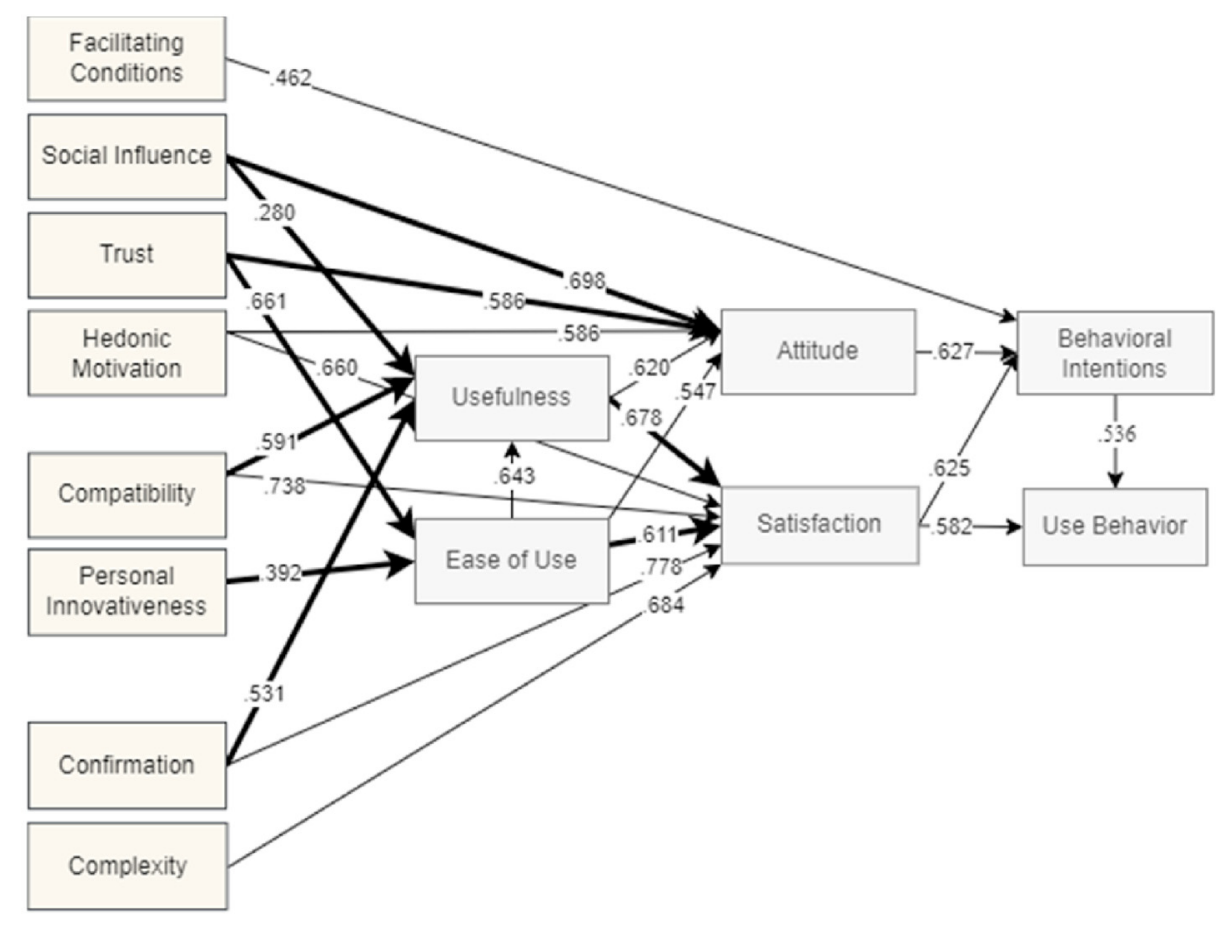

Notes: a) numerical values represent the average $\beta$ with $\mathrm{p}<0.01$; b) bold arrows represent promising predictors; c) regular arrows

represent best predictors.

Figure 4. Proposed model considering different outcomes of UTAUT as results of weight and meta-analysis.

model (DeLone and McLean, 1992), expectation confirmation model (Bhattacherjee, 2001), theory of planned behaviour (Ajzen, 2011), and the unified theory of acceptance and use of technology in both versions (Venkatesh et al., 2003, 2012).

With the proposition of an extended model for technology adoption of DT with an individual focus, we bring new constructs and elements to improve the research field. The model expansion shows the importance of a holistic view for managerial advances (Orsingher et al., 2016), highlighting the need for contextual and social analysis to the already existing complexity of disruptive technology ground (Selander and Jarvenpaa, 2016). DT practices involve introducing digital solutions that require changes in the way people work, changing organizational processes and roles to business model disruption (Kraus et al., 2021). For practical implications, innovative technology needs to be compatible with individual and organizational problems, considering the values and experiences of adopters (Selander and Jarvenpaa, 2016). The importance of individual satisfaction as an outcome reflects the success of DT, measured by consumers, customers, citizens, and employees as technology adopters. Network of individuals' relationships and organizational context provide essential resources and infrastructure to disruptive technology adoption. Managers need to consider technology compatibility for users or organizations adopting new technologies since it brings the challenge of supplanting an already known ecosystem through changes (Blut et al., 2021).

The impact of the constructs risk and privacy risk shows the importance of information management for individuals and the need to minimize risks through management to ensure that rules are followed, reducing possible barriers for the transformative initiatives (Nadkarni and Prügl, 2021). The importance of attitude, intention, and use of disruptive technologies, and the need for investments in user-client experience was also revealed, as friendly platforms should offer useful and relevant information, be attractive, intuitive, and easy to use, increasing customer interaction, satisfaction, and performance (Gupta et al., 2020; Harrati et al., 2016). Managers should be aware of the factors related to digital technology adoption by consumers and customers, such as fun or pleasure, habit strength, transaction costs, and the relations among cost/benefit and time/effort. Blut et al. (2021) identified habit as the standout predictor among the original ones and stated personal innovativeness as a key characteristic for technology adoption decisions.

Considering the model results shown in Figure 4, we can state the importance of variables such as satisfaction and attitude impacting behavioral intentions and usage behavior for DT, also acting as mediators of other variables. In this sense, to encourage the use of DT tools, managers should focus on user attitude, satisfaction, and the precursor factors. For satisfaction, it is crucial to consider social influence from family and close friends, user confidence, fun or pleasure, ease of use, and all the benefits for users. For satisfaction, managers can be aware of the perception of difficulty in understanding and using some innovation, ease of use, usefulness, validation of the individual's basic expectations after interaction, fun, and pleasure, and tool compatibility. The perception of support and available resources is a precursor of behavioral intentions for using the DT tool.

The moderation analysis reflects that individualism, as a cultural factor, human capital and research, and knowledge \& technology output, as innovative factors, amplify the strength of the relationship between behavioral intentions to usefulness and ease of use for individual DT adoption. Managers should invest in employees' capabilities and autonomy by promoting IT champions (Harrati et al., 2016), as group management can be less important than managing individual needs (Hofstede, 2001). Given the findings in the innovation context, the moderation role of human capital and research highlights the importance of employee training and development investments (Švarc et al., 2020). The indicator knowledge \& technology innovation output denotes the need for an ideal environment for constant diffusion and exchange of knowledge among individuals (Guggemos and Seufert, 2021; Pillet and Carillo, 2016), strengthening ease of use and usefulness perceptions to adopt DT technologies. 


\subsection{Limitations and future research}

This work has several limitations. First, not all studies on DT adoption were included since many presented different statistical methods, did not contain sufficient quantitative data, or were not presented in the English language, including lacunae in sample data and statistical correlation values. Research scope expansion allows the inclusion of publications with diverse statistical methods to new analysis with comprehensive results. Second, additional attention should be given to the magnitude of DT's risk and privacy risk variables, even after non-statistically significant results, requiring additional research due to the considerable value of their relationship with use behavior and attitude. Vimalkumar et al. (2021) stated that privacy risk is mediated by privacy concerns and trust for disruptive technology adoption. Third, most publications do not have information about survey items, making it impossible to identify certain similarities among variables and limiting the coding and merging process. In this research, not all variables with similar nomenclature present similarity of meaning, as illustrated in Table 1 . Fourth, few moderating dimensions were considered, bringing economic, cultural, and innovation contexts. Culture is an essential factor in technology adoption (Srite and Karahanna, 2006), and future studies should consider not only four dimensions (Hofstede, 2001) but all others (Blut et al., 2021). Including new relevant moderators for DT individual adoption can be relevant as user characteristics (Blut et al., 2021), technology, or sample type (Santini et al., 2019). Finally, as DT adoption can be understood from an individual or organizational view, we recommend carrying out a meta-analysis about firms' views to provide a complete perception by comparing individual and firms' adoption factors.

\section{Conclusions}

DT has gained strength and importance in academic and practical contexts, impacting people's lives, given the acceleration in the adoption of disruptive technologies brought about by the pandemic implications. To understand this context, a weight and meta-analysis was carried out to synthesize and aggregate previous literature to advance the theme, suggesting new constructs and relations for further investigation. After a literature review, 88 publications and 99 datasets were found, comprising 442 relevant relationships, considering those examined at least three times in the literature. The weight and meta-analysis made it possible to analyze relations, clarifying 46 statistically significant relationships out of 48. Constructs of great impact in individual adoption literature were identified and presented through a theoretical model that extends existing academic research and innovates, proposing new outcomes for disruptive technology adoption. For Blut et al. (2021), meta-analysis can lead to the precise specification of some theory applied to a context, given the variability of user type, national cultural aspects, and technologies applied in previous research. This weight and meta-analysis contributed to overcoming conflicting results from the primary studies presented. For example, we showed the existence of a positive and moderate relationship between ease of use and behavioral intentions, convergent with Khaksar et al. (2021) and contrary to Vimalkumar et al. (2021), which showed a negative relationship. Another positive and moderate relationship found by us was among usefulness and behavioral intentions, similar to Kabir (2020) and contrary, as shown by Nastjuk et al. (2020).

As significant contributions for the DT field of study, our results highlighted that attitude and satisfaction are relevant predictors of behavioral intentions and are promising outcomes for further investigation, including compatibility and personal innovativeness. Behavioral intentions, satisfaction, and habit are the best predictors for disruptive technology use. Usefulness and ease of use play a critical role in DT, influencing outcomes like intention, use, satisfaction, and attitude, moderated by cultural and innovative contexts. Individualism, representing the cultural aspect and the indicators of human capital and research, and knowledge and technology output, as the innovative element, moderate the relationship between behavioral intentions to usefulness and ease of use. Contributions made after presenting the results provide an update on DT's state of the art combined with individual technology adoption, bringing advantages for future research.

\section{Declarations}

\section{Author contribution statement}

Diego Cavalcanti: Conceived and designed the experiments; Performed the experiments; Analyzed and interpreted the data; Contributed reagents, materials, analysis tools or data; Wrote the paper.

Tiago Oliveira: Conceived and designed the experiments; Contributed reagents, materials, analysis tools or data; Wrote the paper.

Fernando de Oliveira Santini: Analyzed and interpreted the data; Wrote the paper.

\section{Funding statement}

This work was supported by national funds through FCT (Fundação para a Ciência e a Tecnologia) under the project - UIDB/04152/2020 Centro de Investigação em Gestão de Informação (MagIC).

\section{Data availability statement}

No data was used for the research described in the article.

Declaration of interests statement

The authors declare no conflict of interest.

\section{Additional information}

No additional information is available for this paper.

\section{References}

Agarwal, R., Karahanna, E., 2000. Time flies when you're having fun: cognitive absorption and beliefs about information technology usage. MIS Q. 24 (3), 665-694. Ajzen, I., 2011. The theory of planned behaviour: reactions and reflections. In: Psychology and Health, 26. Issue 9.

Alam, M.M.D., Alam, M.Z., Rahman, S.A., Taghizadeh, S.K., 2021. Factors influencing mHealth adoption and its impact on mental well-being during COVID-19 pandemic: a SEM-ANN approach. J. Biomed. Inf. 116.

Alam, M.Z., Hu, W., Kaium, M.A., Hoque, M.R., Alam, M.M.D., 2020. Understanding the determinants of mHealth apps adoption in Bangladesh: a SEM-Neural network approach. Technol. Soc. 61.

Alarabiat, A., Soares, D., Estevez, E., 2021. Determinants of citizens' intention to engage in government-led electronic participation initiatives through Facebook. Govern. Inf. Q. 38 (1).

Albashrawi, M., Motiwalla, L., 2020. An integrative framework on mobile banking success. Inf. Syst. Manag. 37 (1).

Aldossari, M.Q., Sidorova, A., 2020. Consumer acceptance of internet of things (IoT): smart home context. J. Comput. Inf. Syst. 60 (6).

Aparicio, M., Costa, C.J., Moises, R., 2021. Gamification and reputation: key determinants of e-commerce usage and repurchase intention. Heliyon 7 (3).

Aswani, R., Ilavarasan, P.V., Kar, A.K., Vijayan, S., 2018. Adoption of public WiFi using UTAUT2: an exploration in an emerging economy. Procedia Comput. Sci. 132.

Balakrishnan, V., Shuib, N.L.M., 2021. Drivers and inhibitors for digital payment adoption using the Cashless Society Readiness-Adoption model in Malaysia. Technol. Soc. 65.

Bandura, A., 1986. Social Foundations of Thought and Action : a Social Cognitive theory/ Albert Bandura, 16. Prentice-Hall, New Jersey (1).

Baptista, G., Oliveira, T., 2019. Gamification and serious games: a literature meta-analysis and integrative model. In: Computers in Human Behavior, 92.

Baudier, P., Ammi, C., Deboeuf-Rouchon, M., 2020. Smart home: highly-educated students' acceptance. Technol. Forecast. Soc. Change 153.

Ben Arfi, W., Ben Nasr, I., Khvatova, T., Ben Zaied, Y., 2021a. Understanding acceptance of eHealthcare by IoT natives and IoT immigrants: an integrated model of UTAUT, perceived risk, and financial cost. Technol. Forecast. Soc. Change 163.

Ben Arfi, W., Ben Nasr, I., Kondrateva, G., Hikkerova, L., 2021b. The role of trust in intention to use the IoT in eHealth: application of the modified UTAUT in a consumer context. Technol. Forecast. Soc. Change 167.

Bhattacherjee, A., 2001. Understanding information systems continuance: an expectationconfirmation model. MIS Q.: Manag. Inf. Syst. 25 (3). 
Blut, M., Chong, A., Tsiga, Z., Venkatesh, V., 2021. Meta-analysis of the unified theory of acceptance and use of technology (UTAUT): challenging its validity and charting A research agenda in the red ocean. J. Assoc. Inf. Syst. Online. http://dro.dur.ac. uk/32972/.

Bölen, M.C., 2020. From traditional wristwatch to smartwatch: understanding the relationship between innovation attributes, switching costs and consumers' switching intention. Technol. Soc. 63.

Borenstein, M., Hedges, L.V., Higgins, J.P.T., Rothstein, H.R., 2009. Introduction to metaanalysis. In: Introduction to Meta-Analysis.

Cabrera-Sánchez, J.P., Villarejo-Ramos, Á.F., Liébana-Cabanillas, F., Shaikh, A.A., 2021. Identifying relevant segments of AI applications adopters - expanding the UTAUT2's variables. Telematics Inf. 58.

Carroll, N., 2020. Theorizing on the normalization of digital transformations. In: European Conference on Information Systems (ECIS), May.

Çera, G., Pagria, I., Khan, K.A., Muaremi, L., 2020. Mobile banking usage and gamification: the moderating effect of generational cohorts. J. Syst. Inf. Technol. 12 (3).

Cha, K.J., Hwang, T., Gregor, S., 2015. An integrative model of IT-enabled organizational transformation: a multiple case study. Manag. Decis. 53 (8).

Chakraborty, S., Bhatt, V., Chakravorty, T., 2020. Impact of digital technology adoption on care service orchestration, agility and responsiveness. Int. J. Sci. Technol. Res. 9 (3).

Chakraborty, S., Bhatt, V., Chakravorty, T., Chakraborty, K., 2021. Analysis of digital technologies as antecedent to care service transparency and orchestration. Technol. Soc. 65.

Chandra, S., Shirish, A., Srivastava, S.C., 2020. Theorizing technological spatial intrusion for ICT enabled employee innovation: the mediating role of perceived usefulness. Technol. Forecast. Soc. Change 161.

Chen, S.C., Yen, D.C., Peng, S.C., 2018a. Assessing the impact of determinants in emagazines acceptance: an empirical study. Comput. Stand. Interfac. 57.

Chen, Y., Yang, L., Zhang, M., Yang, J., 2018b. Central or peripheral? Cognition elaboration cues' effect on users' continuance intention of mobile health applications in the developing markets. Int. J. Med. Inf. 116.

Chopdar, P.K., Korfiatis, N., Sivakumar, V.J., Lytras, M.D., 2018. Mobile shopping apps adoption and perceived risks: a cross-country perspective utilizing the Unified Theory of Acceptance and Use of Technology. Comput. Hum. Behav. 86.

Coccia, M., 2020. Factors Determining the Diffusion of COVID-19 and Suggested Strategy to Prevent Future Accelerated Viral Infectivity Similar to COVID. Science of the Total Environment, p. 729.

Cram, W.A., D'Arcy, J., Proudfoot, J.G., 2019. Seeing the forest and the trees: a metaanalysis of the antecedents to information security policy compliance. MIS Q.: Manag. Inf. Syst. 43 (2), 525-554.

Davis, F.D., 1989. Perceived usefulness, perceived ease of use, and user acceptance of information technology. MIS Q. 13 (3), 319-340. http://search.ebscohost.com login.aspx?direct=true\&amp;site=eds-live\&amp; db=bth\&amp;AN=4679168.

Delgosha, M.S., Hajiheydari, N., 2020. On-demand service platforms pro/anti adoption cognition: examining the context-specific reasons. J. Bus. Res. 121.

DeLone, W.H., McLean, E.R., 1992. Information systems success: the quest for the dependent variable. Inf. Syst. Res. 3 (1), 60-95.

Dodds, W.B., Monroe, K.B., Grewal, D., 1991. Effects of price, brand, and store information on buyers' product evaluations. J. Market. Res. 28 (3).

El-Haddadeh, R., Weerakkody, V., Osmani, M., Thakker, D., Kapoor, K.K., 2019. Examining citizens' perceived value of internet of things technologies in facilitating public sector services engagement. Govern. Inf. Q. 36 (2).

El-Masri, M., Tarhini, A., 2017. Factors Affecting the Adoption of E-Learning Systems in Qatar and USA: Extending the Unified Theory of Acceptance and Use of Technology 2 (UTAUT2). Educational Technology Research and Development.

Featherman, M.S., Pavlou, P.A., 2003. Predicting e-services adoption: a perceived risk facets perspective. Int. J. Hum. Comput. Stud. 59 (4).

Fishbein, M., Ajzen, I., 1975. Beliefs, attitude, intention, and behavior. In: Strategies of Change: Persuasive Communication.

Franque, F.B., Oliveira, T., Tam, C., 2021. Understanding the factors of mobile payment continuance intention: empirical test in an African context. Heliyon 7 (8).

Franque, F.B., Oliveira, T., Tam, C., Santini, F. de O., 2020. A meta-analysis of the quantitative studies in continuance intention to use an information system. Internet Res. 31 (Issue 1).

Fu, J.R., Farn, C.K., Chao, W.P., 2006. Acceptance of electronic tax filing: a study of taxpayer intentions. Inf. Manag. 43 (1).

Gefen, D., Karahanna, E., Straub, D.W., 2003. Trust and tam in online shopping: AN integrated model. MIS Q.: Manag. Inf. Syst. 27 (1).

Gerow, J.E., Grover, V., Thatcher, J., Roth, P.L., 2014. Looking toward the future of ITbusiness strategic alignment through the past: a meta-analysis. MIS Q.: Manag. Inf. Syst. 38 (4).

Geyskens, I., Krishnan, R., Steenkamp, J.B.E.M., Cunha, P.V., 2009. A review and evaluation of meta-analysis practices in management research. J. Manag. 35 (2).

Guggemos, J., Seufert, S., 2021. Teaching with and teaching about technology - evidence for professional development of in-service teachers. Comput. Hum. Behav. 115.

Gupta, A., Yousaf, A., Mishra, A., 2020. How pre-adoption expectancies shape postadoption continuance intentions: an extended expectation-confirmation model. Int. J. Inf. Manag. 52.

Guy, J.S., 2019. Digital technology, digital culture and the metric/nonmetric distinction. Technol. Forecast. Soc. Change 145.

Hajiheydari, N., Delgosha, M.S., Olya, H., 2021. Scepticism and Resistance to IoMT in Healthcare: Application of Behavioural Reasoning Theory with Configurational Perspective, 169. Technological Forecasting and Social Change.
Hao, S., Dennen, V.P., Mei, L., 2017. Influential factors for mobile learning acceptance among Chinese users. Educ. Technol. Res. Dev. 65 (1).

Harrati, N., Bouchrika, I., Tari, A., Ladjailia, A., 2016. Exploring user satisfaction for elearning systems via usage-based metrics and system usability scale analysis. Comput. Hum. Behav. 61.

He, T., Huang, Q., Yu, X., Li, S., 2020. Exploring Students' Digital Informal Learning: the Roles of Digital Competence and DTPB Factors. Behaviour and Information Technology.

Hofstede, G., 2001. Geert Hofstede, Culture's Consequences: Comparing Values, Behaviours, Institutions, and Organizations across Nations. Sage Publications.

Huang, D.H., Chueh, H.E., 2020. Chatbot usage intention analysis: veterinary consultation. J. Innov, Knowl.

Hu, G., Chohan, S.R., Liu, J., 2020. Does IoT service orchestration in public services enrich the citizens' perceived value of digital society? Asian J. Technol. Innovat.

Hujran, O., Abu-Shanab, E., Aljaafreh, A., 2020. Predictors for the adoption of edemocracy: an empirical evaluation based on a citizen-centric approach. Transforming Gov. People, Process Policy 14 (3).

Hu, Z., Ding, S., Li, S., Chen, L., Yang, S., 2019. Adoption intention of fintech services for bank users: an empirical examination with an extended technology acceptance model. Symmetry 11 (3).

Jadil, Y., Rana, N.P., Dwivedi, Y.K., 2021. A meta-analysis of the UTAUT model in the mobile banking literature: the moderating role of sample size and culture. J. Bus. Res. 132, 354-372.

Jahanmir, S.F., Silva, G.M., Gomes, P.J., Gonçalves, H.M., 2020. Determinants of users' continuance intention toward digital innovations: are late adopters different? J. Bus. Res. 115.

Jain, G., Paul, J., Shrivastava, A., 2021. Hyper-personalization, co-creation, digital clienteling and transformation. J. Bus. Res. 124.

Jaklič, J., Grublješič, T., Popovič, A., 2018. The role of compatibility in predicting business intelligence and analytics use intentions. Int. J. Inf. Manag. 43.

Jetter, J., Eimecke, J., Rese, A., 2018. Augmented reality tools for industrial applications: what are potential key performance indicators and who benefits? Comput. Hum. Behav. 87.

Jeyaraj, A., Rottman, J.W., Lacity, M.C., 2006. A review of the predictors, linkages, and biases in IT innovation adoption research. J. Inf. Technol. 21 (Issue 1).

Johnson, V.L., Kiser, A., Washington, R., Torres, R., 2018. Limitations to the rapid adoption of M-payment services: understanding the impact of privacy risk on MPayment services. Comput. Hum. Behav. 79.

Kabir, M.R., 2020. Behavioural intention to adopt blockchain for a transparent and effective taxing system. J. Global Oper. Strat. Sour. 14 (1).

Kamolsook, A., Badir, Y.F., Frank, B., 2019. Consumers' switching to disruptive technology products: the roles of comparative economic value and technology type. Technol. Forecast. Soc. Change 140.

Kane, G., 2019. The technology fallacy: people are the real key to digital transformation. Res. Technol. Manag. 62 (6).

Kar, S., Kar, A.K., Gupta, M.P., 2021. Industrial Internet of Things and Emerging Digital Technologies-Modeling Professionals' Learning Behavior, 9. IEEE Access.

Khaksar, S.M.S., Khosla, R., Singaraju, S., Slade, B., 2021. Carer's perception on social assistive technology acceptance and adoption: moderating effects of perceived risks. Behav. Inf. Technol. 40 (4).

Khan, S.U., Liu, X.dong, Liu, C., Khan, I.U., Hameed, Z., 2020. Understanding uncertainty dimensions and Internet stock trading service in China from a social cognitive perspective. Inf. Technol. People 34 (2).

Khoa, B.T., 2020. The role of mobile skillfulness and user innovation toward electronic wallet acceptance in the digital transformation era. In: 2020 International Conference on Information Technology Systems and Innovation, ICITSI 2020 - Proceedings.

Kim, Y., Peterson, R.A., 2017. A meta-analysis of online trust relationships in Ecommerce. J. Interact. Market. 38.

Kraus, S., Schiavone, F., Pluzhnikova, A., Invernizzi, A.C., 2021. Digital transformation in healthcare: analyzing the current state-of-research. J. Bus. Res. 123.

Kummer, T.F., Recker, J., Bick, M., 2017. Technology-induced anxiety: manifestations, cultural influences, and its effect on the adoption of sensor-based technology in German and Australian hospitals. Inf. Manag. 54 (1).

Kunz, R.E., Santomier, J.P., 2019. Sport content and virtual reality technology acceptance. Sport Bus. Manag.: Int. J. 10 (1).

Lau, A.J., Tan, G.W.-H., Loh, X.-M., Leong, L.-Y., Lee, V.-H., Ooi, K.-B., 2021. On the way: hailing a taxi with a smartphone? A hybrid SEM-neural network approach. Machine Learn. Appl. 4.

Liébana-Cabanillas, F., García-Maroto, I., Muñoz-Leiva, F., Ramos-de-Luna, I., 2020a. Mobile payment adoption in the age of digital transformation: the case of apple pay. Sustainability 12 (13).

Liébana-Cabanillas, F., Japutra, A., Molinillo, S., Singh, N., Sinha, N., 2020b. Assessment of mobile technology use in the emerging market: analyzing intention to use mpayment services in India. Telecommun. Pol. 44 (9).

Li, H., Gupta, A., Zhang, J., Sarathy, R., 2014. Examining the decision to use standalone personal health record systems as a trust-enabled fair social contract. Decis. Support Syst. 57 (1).

Lin, H.C., Tu, Y.F., Hwang, G.J., Huang, H., 2021. From precision education to precision medicine: factors affecting medical staff's intention to learn to use AI applications in hospitals. Educ. Technol. Soc. 24 (1).

Li, P.C., Kong, W.J., Zhou, W.L., 2020. Research on the Mobile Learning Adoption of College Students Based on TTF and UTAUT. ACM International Conference Proceeding Series.

Mamonov, S., Benbunan-Fich, R., 2020. Unlocking the smart home: exploring key factors affecting the smart lock adoption intention. Inf. Technol. People 34 (2). 
Manfreda, A., Ljubi, K., Groznik, A., 2021. Autonomous vehicles in the smart city era: an empirical study of adoption factors important for millennials. Int. J. Inf. Manag. 58

Mariani, M.M., Ek Styven, M., Teulon, F., 2021. Explaining the intention to use digital personal data stores: an empirical study. Technol. Forecast. Soc. Change 166.

Martínez-Caro, E., Cegarra-Navarro, J.G., García-Pérez, A., Fait, M., 2018. Healthcare service evolution towards the Internet of Things: an end-user perspective. Technol. Forecast. Soc. Change 136.

Matt, C., Hess, T., Benlian, A., 2015. Digital transformation strategies. In: Business and Information Systems Engineering, 57. Issue 5.

Meng, F., Guo, X., Peng, Z., Zhang, X., Vogel, D., 2019. The routine use of mobile health services in the presence of health consciousness. Electron. Commer. Res. Appl. 35.

Mergel, I., Edelmann, N., Haug, N., 2019. Defining digital transformation: results from expert interviews. Govern. Inf. Q. 36 (4).

Meske, C., Junglas, I., 2020. Investigating the Elicitation of Employees' Support towards Digital Workplace Transformation. Behaviour and Information Technology.

Milanović, N., Milosavljević, M., Benković, S., Starčević, D., Spasenić, Ž., 2020. An acceptance approach for novel technologies in car insurance. Sustainability 12 (24).

Nadkarni, S., Prügl, R., 2021. Digital transformation: a review, synthesis and opportunities for future research. Manag. Rev. Quart. 71 (2).

Naranjo Zolotov, M., Oliveira, T., Casteleyn, S., 2018. E-participation adoption models research in the last 17 years: a weight and meta-analytical review. In: Computers in Human Behavior, 81.

Nastjuk, I., Herrenkind, B., Marrone, M., Brendel, A.B., Kolbe, L.M., 2020. What Drives the Acceptance of Autonomous Driving? an Investigation of Acceptance Factors from an End-User's Perspective, 161. Technological Forecasting and Social Change.

Navaridas-Nalda, F., Clavel-San Emeterio, M., Fernández-Ortiz, R., Arias-Oliva, M., 2020. The strategic influence of school principal leadership in the digital transformation of schools. Comput. Hum. Behav. 112.

Netshirando, V., Munyoka, W., Kadyamatimba, A., 2020. Determinants of digital commerce repeat-purchase behaviour in South Africa: a rural citizen perspective. Afr. J. Sci. Technol. Innov. Develop.

Nguyen, T.T., Nguyen, H.T., Mai, H.T., Tran, T.T.M., 2020. Determinants of digital banking services in Vietnam: applying utaut2 model. Asian Econ. Financ. Rev. 10 (6).

Nikou, S., Agahari, W., Keijzer-Broers, W., de Reuver, M., 2020. Digital healthcare technology adoption by elderly people: a capability approach model. Telematics Inf. 53.

Orbell, S., Hodgkins, S., Sheeran, P., 1997. Implementation intentions and the theory of planned behavior. Pers. Soc. Psychol. Bull. 23 (9).

Orsingher, C., Hogreve, J., Ordanini, A., 2016. Building on the past: advancing theory in services through meta-analysis. J. Service Manag. 27 (1).

Pal, A., Herath, T., De', R., Rao, H.R., 2020. Contextual facilitators and barriers influencing the continued use of mobile payment services in a developing country: insights from adopters in India. Inf. Technol. Dev. 26 (2).

Pal, D., Patra, S., 2021. University students' perception of video-based learning in times of COVID-19: a TAM/TTF perspective. Int. J. Hum. Comput. Interact. 37 (10).

Park, B., Chang, H., Park, S., Steven), 2019. Adoption of digital devices for children education: Korean case. Telematics Inf. 38.

Patil, P., Tamilmani, K., Rana, N.P., Raghavan, V., 2020. Understanding consumer adoption of mobile payment in India: extending Meta-UTAUT model with personal innovativeness, anxiety, trust, and grievance redressal. Int. J. Inf. Manag. 54.

Peña-García, N., Gil-Saura, I., Rodríguez-Orejuela, A., Siqueira-Junior, J.R., 2020. Purchase intention and purchase behavior online: a cross-cultural approach. Heliyon 6 (6).

Pham, T.T.T., Ho, J.C., 2015. The effects of product-related, personal-related factors and attractiveness of alternatives on consumer adoption of NFC-based mobile payments. Technol. Soc. 43.

Pillai, R., Sivathanu, B., Dwivedi, Y.K., 2020. Shopping intention at AI-powered automated retail stores (AIPARS). J. Retailing Consum. Serv. 57.

Pillet, J.C., Carillo, K.D.A., 2016. Email-free collaboration: an exploratory study on the formation of new work habits among knowledge workers. Int. J. Inf. Manag. 36 (1).

Queiroz, M.M., Fosso Wamba, S., 2019. Blockchain adoption challenges in supply chain: an empirical investigation of the main drivers in India and the USA. Int. J. Inf. Manag. 46.

Rafique, H., Alroobaea, R., Munawar, B.A., Krichen, M., Rubaiee, S., Bashir, A.K., 2021. Do digital students show an inclination toward continuous use of academic library applications? A case study. J. Acad. Librarian 47 (2).

Rahi, S., Abd.Ghani, M., Hafaz Ngah, A., 2019. Integration of unified theory of acceptance and use of technology in internet banking adoption setting: evidence from Pakistan. Technol. Soc. 58

Rahman, M.S., Ko, M., Warren, J., Carpenter, D., 2016. Healthcare Technology SelfEfficacy (HTSE) and its influence on individual attitude: an empirical study. Comput. Hum. Behav. 58.

Ray, A., Bala, P.K., Dasgupta, S.A., 2019. Role of authenticity and perceived benefits of online courses on technology based career choice in India: a modified technology adoption model based on career theory. Int. J. Inf. Manag. 47.

Rodger, J.A., 2014. Reinforcing inspiration for technology acceptance: improving memory and software training results through neuro-physiological performance. Comput. Hum. Behav. 38

Rogers, E.M., Singhal, A., Quinlan, M.M., 2019. Diffusion of innovations. In: An Integrated Approach to Communication Theory and Research, third ed.
Saheb, T., 2020. An empirical investigation of the adoption of mobile health applications: integrating big data and social media services. Health Technol. 10 (5).

Santini, F. de O., Vieira, V.A., Sampaio, C.H., Perin, M.G., 2016. Meta-analysis of the longand short-term effects of sales promotions on consumer behavior. J. Promot. Manag. 22 (3).

Santini, F.D.O., Ladeira, W.J., Sampaio, C.H., Perin, M.G., Dolci, P.C., 2019. A metaanalytical study of technological acceptance in banking contexts. Int. J. Bank Market. 37 (3).

Schallmo, D., Williams, C.A., Boardman, L., 2017. Digital transformation of business models-best practice, enablers, and roadmap. Int. J. Innovat. Manag. 21 (Issue 8).

Schikofsky, J., Dannewald, T., Kowald, M., 2020. Exploring Motivational Mechanisms behind the Intention to Adopt Mobility as a Service (MaaS): Insights from Germany, 131. Transportation Research Part A: Policy and Practice.

Schmidthuber, L., Maresch, D., Ginner, M., 2020. Disruptive technologies and abundance in the service sector - toward a refined technology acceptance model. Technol. Forecast. Soc. Change 155.

Scott, S., Hughes, P., Hodgkinson, I., Kraus, S., 2019. Technology adoption factors in the digitization of popular culture: analyzing the online gambling market. Technol. Forecast. Soc. Change 148.

Selander, L., Jarvenpaa, S.L., 2016. Digital action repertoires and transforming a social movement organization. MIS Q.: Manag. Inf. Syst. 40 (2).

Singh, A., Hess, T., 2017. How chief digital officers promote the digital transformation of their companies. MIS Q. Exec. 16 (1).

Sobti, N., 2019. Impact of demonetization on diffusion of mobile payment service in India: antecedents of behavioral intention and adoption using extended UTAUT model. J. Adv. Manag. Res. 16 (4).

So, K.K.F., Oh, H., Min, S., 2018. Motivations and constraints of Airbnb consumers: findings from a mixed-methods approach. Tourism Manag. 67.

Srite, M., Karahanna, E., 2006. The role of espoused national cultural values in technology acceptance. MIS Q.: Manag. Inf. Syst. 30 (3).

Ståhle, P., Ståhle, S., Lin, C.Y.Y., 2015. Intangibles and national economic wealth - a new perspective on how they are linked. J. Intellect. Cap. 16 (1).

Sun, Y., Yang, C., Shen, X.L., Wang, N., 2020. When digitalized customers meet digitalized services: a digitalized social cognitive perspective of omnichannel service usage. Int. J. Inf. Manag. 54.

Švarc, J., Lažnjak, J., Dabić, M., 2020. The role of national intellectual capital in the digital transformation of EU countries. Another digital divide? J. Intellect. Cap. 22 (4).

Taghizadeh, S.K., Rahman, S.A., Nikbin, D., Alam, M.M.D., Alexa, L., Ling Suan, C., Taghizadeh, S., 2021. Factors Influencing Students' Continuance Usage Intention with Online Learning during the Pandemic: a Cross-Country Analysis. Behaviour \& Information Technology.

Teo, T., Zhou, M., Noyes, J., 2016. Teachers and technology: development of an extended theory of planned behavior. Educ. Technol. Res. Dev. 64 (6).

Thakurta, R., Urbach, N., Basu, A., 2020. Understanding technology transition: a crosscultural study on the transition from PCs to tablet computers. Int. J. Technol. Manag. $82(3-4)$.

Udo, G., Bagchi, K., Maity, M., 2016. Exploring factors affecting digital piracy using the norm activation and UTAUT models: the role of national culture. J. Bus. Ethics 135 (3).

Vallerand, R.J., 1997. Toward A hierarchical model of intrinsic and extrinsic motivation. Adv. Exp. Soc. Psychol. 29 (C).

Veiga, J.F., Floyd, S., Dechant, K., 2001. Towards modelling the effects of national culture on IT implementation and acceptance. J. Inf. Technol. 16 (3).

Venkatesh, V., 2000. Determinants of perceived ease of use: integrating control, intrinsic motivation, and emotion into the technology acceptance model. Inf. Syst. Res. 11 (4).

Venkatesh, V., Morris, M.G., Davis, G.B., Davis, F.D., 2003. User acceptance of information technology: toward a unified view. MIS O. 27 (3), 425-478.

Venkatesh, V., Thong, J.Y.L., Xu, X., 2012. Consumer acceptance and use of information technology: extending the unified theory of acceptance and use of technology. MIS Q.: Manag. Inf. Syst. 36 (1).

Venkatesh, V., Thong, J.Y.L., Xu, X., 2016. Unified theory of acceptance and use of technology: a synthesis and the road ahead. J. Assoc. Inf. Syst. Online 17 (5).

Verhoef, P.C., Broekhuizen, T., Bart, Y., Bhattacharya, A., Qi Dong, J., Fabian, N., Haenlein, M., 2021. Digital transformation: a multidisciplinary reflection and research agenda. J. Bus. Res. 122.

Vial, G., 2019. Understanding digital transformation: a review and a research agenda. J. Strat. Inf. Syst. 28 (2).

Vimalkumar, M., Sharma, S.K., Singh, J.B., Dwivedi, Y.K., 2021. 'Okay google, what about my privacy?': user's privacy perceptions and acceptance of voice based digital assistants. Comput. Hum. Behav. 120.

WIPO, 2020. Global Innovation Index 2020. https://www.wipo.int/publications/en/d etails.jsp?id=4514\&amp;plang $=\mathrm{EN}$.

World Economic Forum, 2020. Digital Transformation: Powering the Great Reset. World Economic Forum.

Yan, M., Filieri, R., Raguseo, E., Gorton, M., 2021. Mobile apps for healthy living: factors influencing continuance intention for health apps. Technol. Forecast. Soc. Change 166. 